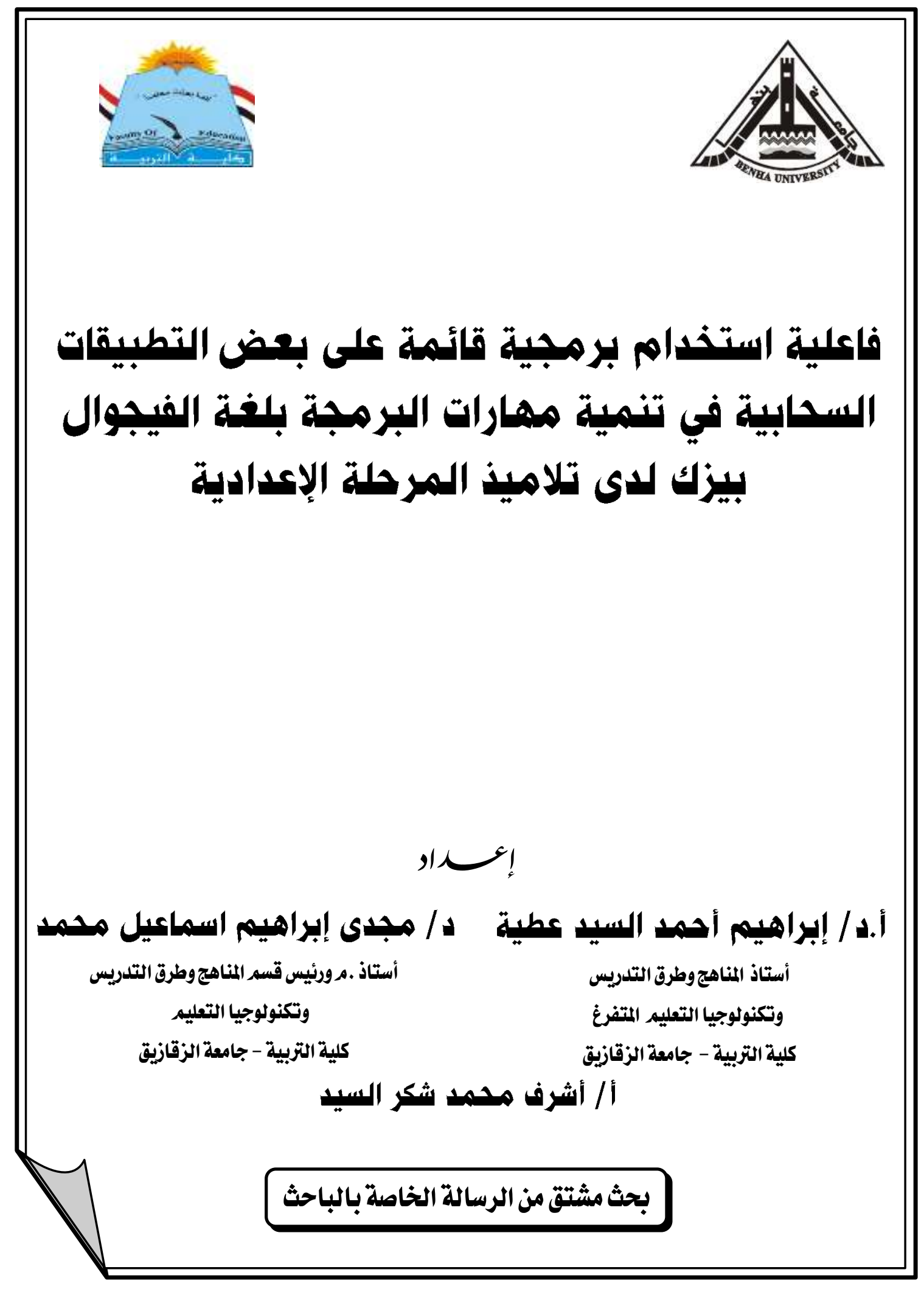




\title{
فاعلية استخداه برمجية قائمة على بعض التطبيقات السحابية في تنمية مهارات البرمجة بلغة الفيدوال بيزك لدى تلاميذ المرحلة الإعدادية
}

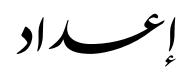

\author{
لـ مجدى إبراهيم اسماعيل محمد \\ أ.د/ إبراهيم أحمد الهيد كطية \\ أستاذ .ـرورئيس قسم المناهجوطرق التلديس \\ أستاذ المناهجوطرق التدريس \\ وتكنولوجيا التعليم

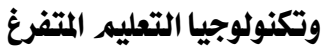 \\ كلية التزبية - جامعة الزقازيق \\ كلية التربية - جامعة الزقازيق التفيق \\ أ أشرف مهمد شكر السيد
}
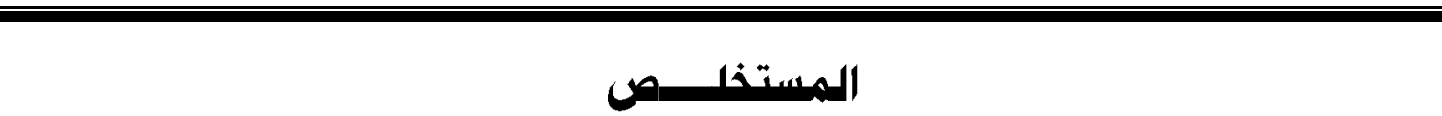

هدفت الدراسة إلى بحث فاعلية استخدام برمجية ق قائمة على بعض التطبيقات السحابية في تتمية مهارات البرمجة بلغة الفيجوال بيزك لدى مجموعة من تلاميذ المرحلة الإعدادية، وقد أجريت الدراسـة على عينة قوامها ( • (7) طالبا قسمت إلى مجموعتين أحدهما تجريبية وعددها ( • (r) تلميذًا، والأخرى ضابطة وعددها ( • (r) تلميذًا، وتضمنت أدوات القياس؛ اختبار تحصيلي لقياس الجوانب المعرفية لمهارات البرمجـة، وبطاقة ملاحظـة لقياس الجانب الأدائي لمهارات البرمجـة، واسـتخدم الباحث مـن حزمـة البـرامج الإحصـائية (SPSS) لتحليـل النتائج؛ اختبـار (ت) لمقارنـة متوسطات الدرجات ومعدل الأداء بين (Independent Samples Test) التطبيق البعدي والقبلي فى الاختبار التحصـيلي وبطاقـة ملاحظـة الأداء للمجموعـة الواحدة، واختبار (ت) لمقارنة متوسطات الدرجات ومعدل الأداء فى (Paired Samples Test) لمي الاختبـار التحصـيلى وبطاقـة ملاحظـة الأداء لـدى تلاميذ المجمـوعتين قبليًا وبعديًا، وتوصـل البحث إلى أن التلاميذ الذين استخدما البرمجية القائمسة على التطبيقيات السحابية أفضل في التحصيل للجانب المعرفي والأداء للجانب الأدائي لمهارات البرمجـة بلغـة الفيجوال بيزك مـن التلاميذ الذين درسوا بالطريقة المعتادة.

الكلمــات المفتاحيـة ؛ برمجيـة تعليميـة، التطبيقات السـحابية، مهارات البرمجـة، فيجـوال بيزك،

$$
\text { المرحلة الإعدادية. }
$$




\section{المقدهمبـالم:}

أدى التطور الكبير في الاتصالات وسرعة انتثار المعلومات عبر الويب بصفة عامـة، وانتشار المعارف الإككترونية بين المتعلمين بصفة خاصة إلى ظهور أدوات تعليمية تعتمد على تطبيقات الويب المختلفة ومنها تطبيقات السحاب الإلكترونية، وحفظ هذه المعارف عبر السحب الإككترونية، والتفاعل معها من خلال هذه التطبيقات، والتي سـاعدت بدورها في حل بعض مشكلات التعليم والتعلم في المناهج الدراسية المختلفة. ويتجه المجتمع حاليًا إلى استخدام برامج وأدوات تكنولوجية تعتمد على خدمات السحابة الإلكترونية في الفضـاء مما دعا الثركات الكبرى في مجال تصميم البرامج إلى بناء تطبيقات

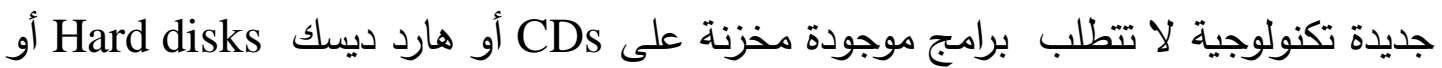
مواقع التحميل والاستضافة File sharing and storage sites، وذلك بكونها تعمل في الفضاء الإلكتروني، وتستخدم خدمات السحابة الإلكترونية (Cloud computing)، كما أشار ماكلوجلين، ولى Mcloughlin\& Lee (2011, 25 إلى وجود أدوات جديدة تختلف عن سابقاتها على الويب مثل نشر الصوت والفيديو عبر الويب.

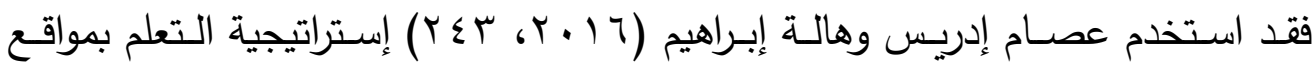
الإنترنت، وتمكّن هذه الإستراتيجية من تقديم مصـادر إلكترونية مختلفة ومتنوعة تُعرض عبر الإنترنت، معتمدة على برامج وخدمات الويب. وهدفت العديد من الدراسات مثل دراسة رشا على إنى

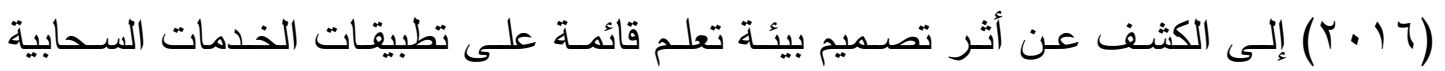
الإككترونيـة لتنميـة مهارات التصمصـم التعليمي، وتوصـلت دراسـة هبـة محمد (T ا ـ ب) التي هدفت إلى قياس فاعلية برنامج تدريبي قائم على الحوسبة السحابية في تتمية بعض المهارات المهنية لدى مسئولي وحدات تدريب المعلمين إلى أن مثل هذه التقنيات الحديثة في مجال الإنترنت تؤدي إلى رفع كفاءة التدريب من حيث التفاعل والمشاركة الإيجابية وسهولة الوصول للبرنـامج في الزمان والمكان الذي يحتاج فيـه المتدرب إلى التعلم، بـل إن تصديم البرمجيات التعليمية باستخدام التطبيقات السحابية (الفضـاء الإلكتروني) هي نتيجة التطور المستمر في

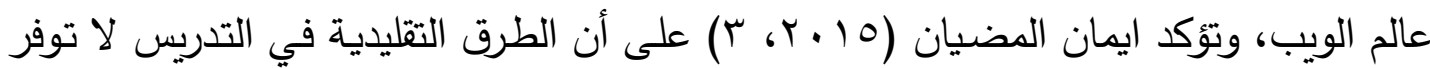
للدارسين الخبرات التعليمية والمعرفية التي تمكنه من متابعة مطالب الوقت الحاضر، والتصدي لمشكلات المناهج التعليمية، ويحتاج المتعلم إلى اكتساب مهارات لحل مثل هذه المشكلات.

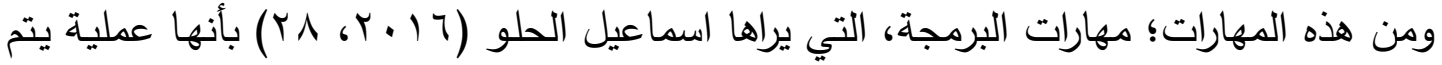


من خلالها تغذية الحاسوب بالأوامر الدقيقة والتفصيلية من أجل إيجاد الحلول لمشكلة ما، ويتم

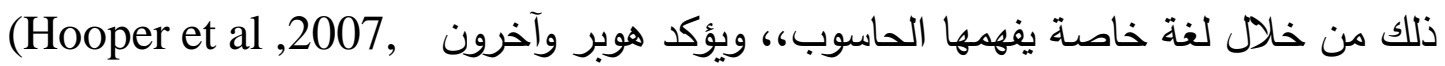
(916 على أن عملية تعلم البرمجـة مـن المهام الصـعبة على الطـلاب المبتدئين ممـا دعت

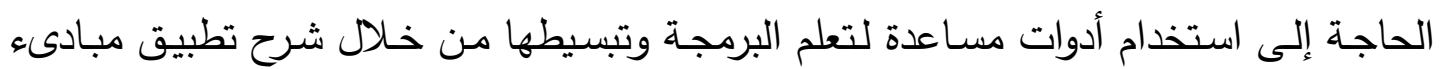

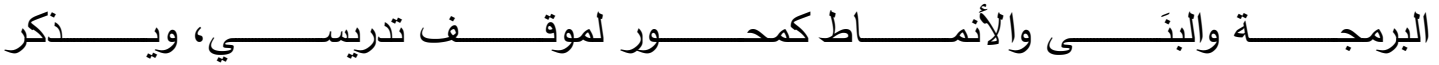

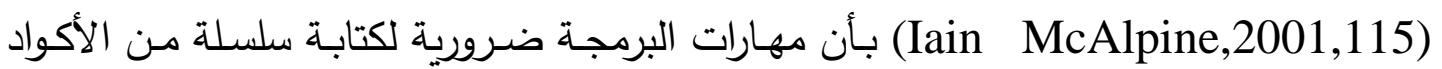
والرموز الخاصة لتنفيذ أوامر معينة ومحدة سلفًا من قبل المبرمج.

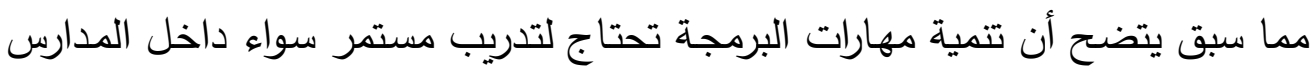

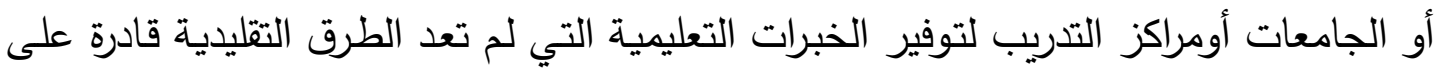

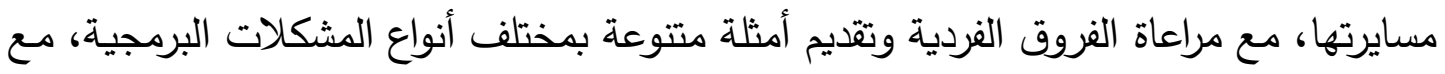

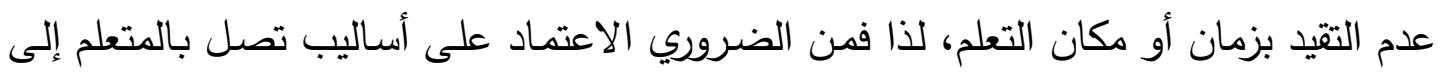
اكتثاف الحلول للمشكلات البرمجية من خلال تتمية مهارات البرمجة.

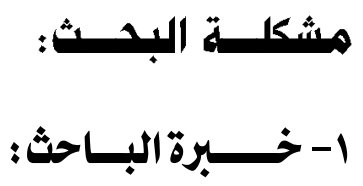

تتبلور مشكلة البحث في وجود تدنٍ في مهارات البرمجة لدى تلاميذ المرحلة الإعدادية،

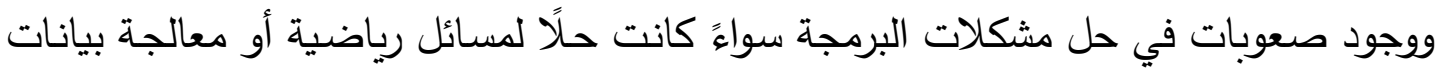
للحصول منهاعلى معلومات، ولتخطي هذه الصعوبات يحتاج المتعلم مجموعة من المهارات

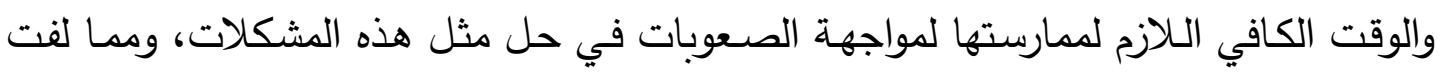

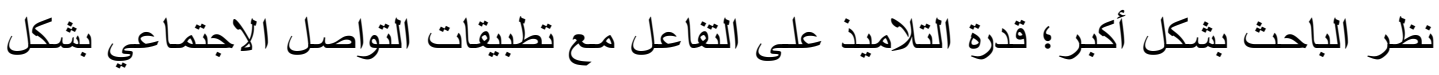

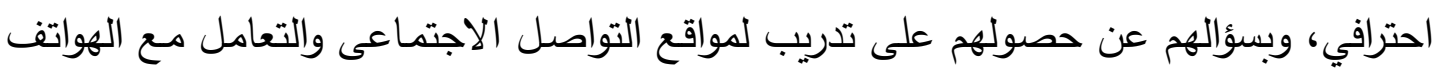
النقالة، أكدوا على أنهم لم يحصلوا على تدريب، ولكنهم يحصلون على على ما يحتاجونه من خلال مشاهدة شروحات عبر الإنترنت، أو سؤال زملائهم.

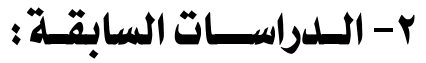

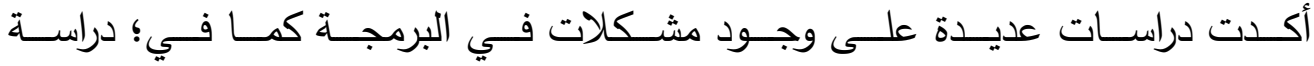

(Kranch, 2010) 
مشكلة في التعليم، والصعوبة في تدريس البرمجة تأتي من إهمال تدريس مهارات حل المشكلات العامة. ودراسة (2008, Bennedesen\& Caspersen) تؤكد أن الطلاب يرون بشكل عام أن مقررات البرمجـة صـعبة -خاصـة بالنسبة للمبتدئين - ولا يستطيعون الانـماج بـالمقرر وبالتالي فإن تعليم البرمجة لمجموعة من المتعلمين هي مشكلة في حد ذاتها، ودراسة داليا الفقي

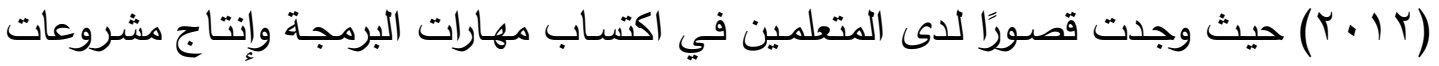

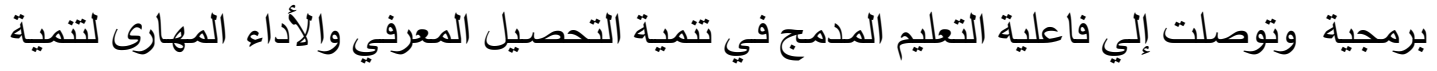
مهارات تصميم وإنتاج مشروعات البرمجة الثيئية بالكائنات، ودراسة رشا رجب (r ( ب ب) حيث

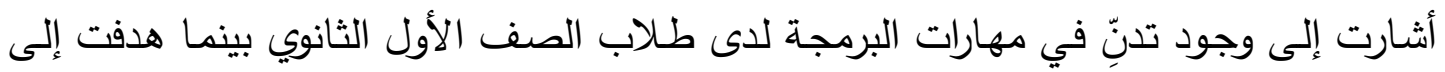

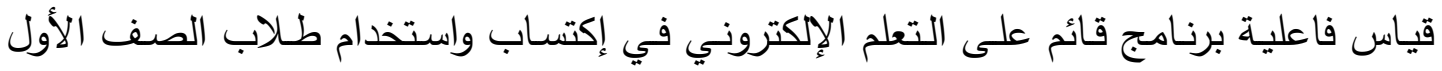

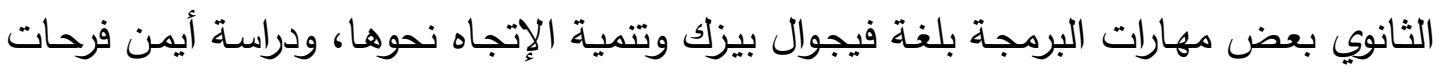

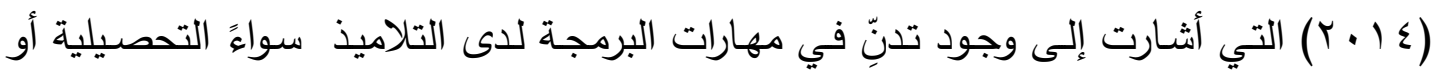

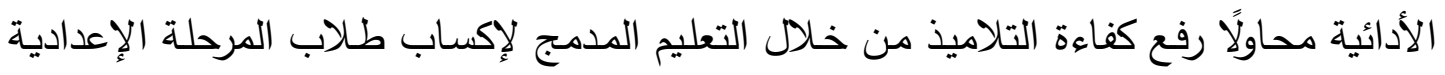
مهارات البرمجة بلغة الفيجول بيزك دوت نت Visual Basic.Net، وتوصلت الدراسة إلى الى وجود فرق دال إحصائيا لصالح المجموعة التجريبية في الاختبار التحصيلي وبطاقة الملاحظة. بينما أكدت بعض الدراسات على إمكانية تعلم البرمجة برغم اختلاف السعة العقلية مثل

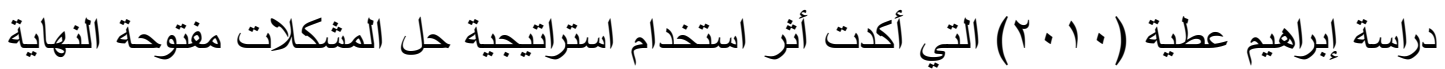

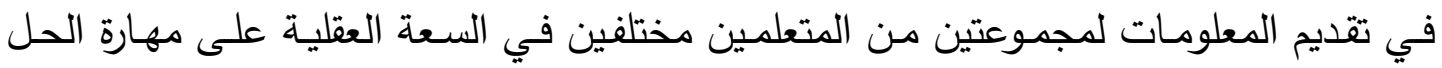

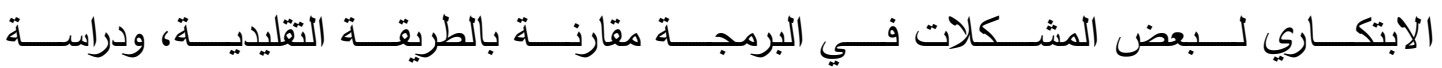
(Michael,Gheorgita,2014,169-174) بوصفها بناءً واحدًا تركز على الذكاء فقط قد لا يكون مناسبًا فى مجال حل مشكلات البرمجة،

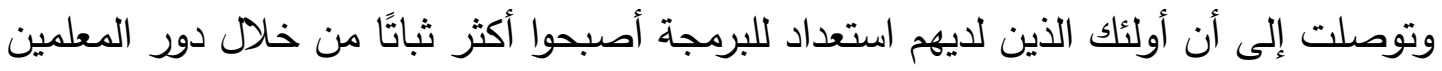
فى الدورات التمهيدية لتصميم وتتييم البرمجيات. وأكدت بعض الدراسات على استخدام تطبيقات الويب في دعم الأنشطة والمهارات مثل الن دراسة (Garofalakis et al,2013) التي هدفت إلى دمج أدوات الويب في التعليم، وأظهرت

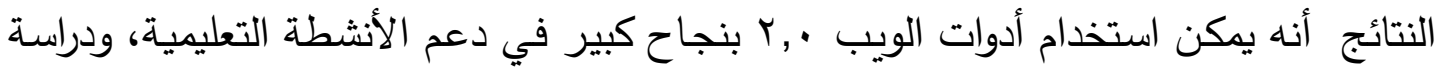

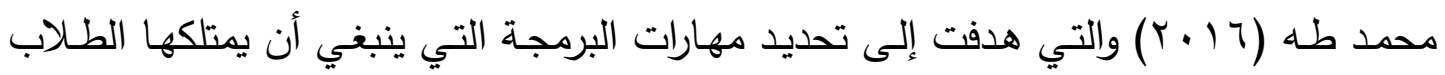

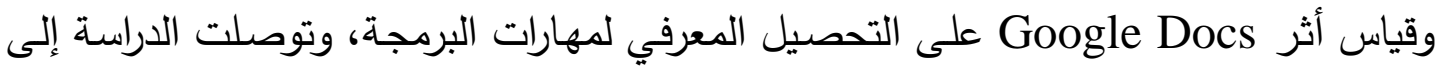


وجـود فـرق دال إحصـائيًا بـين طـلاب المجموعـة التجريبـة الأولـى التـي تـدرس باسـتخدام (Facebook) وطلاب المجموعة التجريبية الثانية التي تدرس باستخدام (Google Docs)

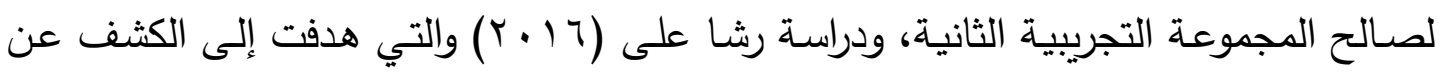

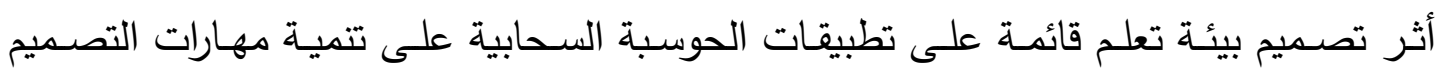

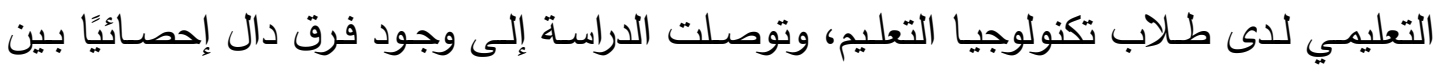
متوسط درجات طلاب عينة البحث في التطبيقين القبلي والبعدي للاختبار التحصيلي، وبطاقة

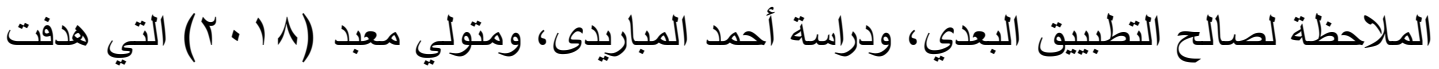

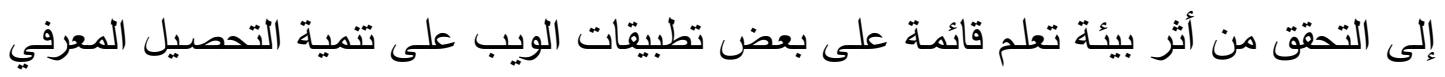

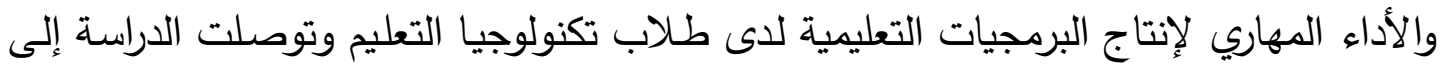

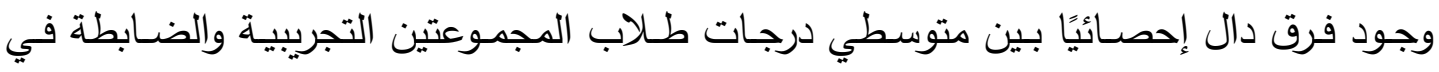
الاختبار التحصيلي، وبطاقة الملاحظة لصالح طلاب المجموعة التجريبية. ومما سبق طرحه من استخدامات للتطبيقات السحابية وأثرها في عملية التعلم وتتمية المهارات، ولوجود مشكلة في تدني مهارات البرمجة لدى تلاميذ المرحلة الإعدادية، سيحاول

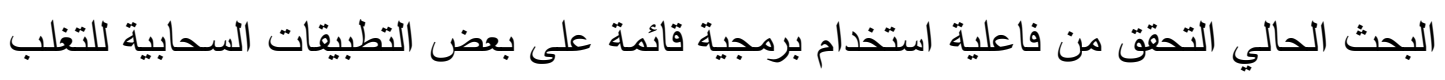
على تدني مهارات البرمجة لدى تلاميذ المرحلة الإعدادية، ويمكن معالجة مشكلة البحث من

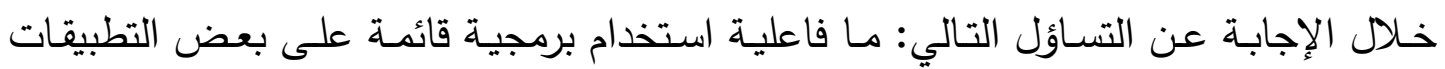
السحابية في تتمية مهارات البرمجة لاى تلاميذ المرحلة الإعدادية؟ ويتفرع من ذلك الأسئلة التالية: • ما المهارات الأساسية الواجب تتميتها لدى تلاميذ المرحلة الإعدادية؟ • ما التصور المقترح لبرمجية قائمة على بعض التطبييقات السحابية لتتمية مهارات البرمجة لاى تلاميذ المرحلة الإعدادية؟ ما فاعلية استخدام برمجية قائمة على بعض التطبيقات السحابية في تتمية الجوانب المعرفية لـهارات البرمجة لاى تلاميذ المرحلة الإعدادية؟

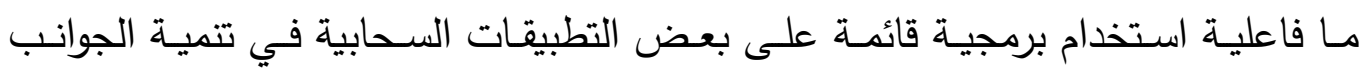

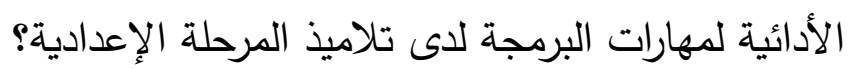




\section{أهــافت البدثـث: \\ يهرف البحث الحالي إلى:}

1- تحديد مهارات البرمجة في لغة الفيجوال بيزلك Visual Basic .Net للى تلاميذ المرحلة

$$
\text { الإعدادية. }
$$

ץ-تصميم برمجية قائمة على بعض تطبيقات الخدمات السحابية الإلكترونية لتتمية مهارات

$$
\text { البرمجة لاى تلاميذ المرحلة الإعدادية. }
$$

r- التعرف على فاعلية استخدام بعض تطبيقات الخدمات السحابية الإككترونية في الجوانب الإنبة المعرفية لمهارات البرمجة بلغة الفيجوال بيزك لدى تلاميذ المرحلة الإعدادية.

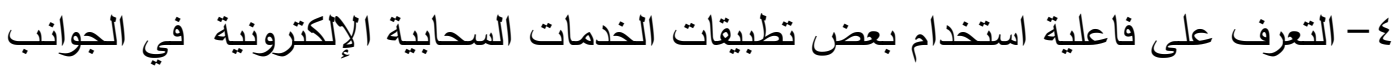

الأدائية لمهارات البرمجة بلغة الفيجوال بيزك لاعى تلاميذ المرحلة الإعدادية.

1-توظيف بعض تطبيقات الخدمات السحابية الإلكترونية كمعالجة تجربيـة مقترحة لدى

$$
\text { تلاميذ المرحلة الإعدادية. }
$$

r- تحسين الجانب المعرفي والأدائي في مهارات البرمجة بلغة الفيجوال بيزك لدى تلاميذ

$$
\text { المرحلة الإعدادية. }
$$

r- اسـتخدام أدوات وتطبيقـات الخدمات الســابية الإلكترونيـة في التعليم لتتميـة مهـارات

$$
\text { البرمجة لدى تلاميذ المرحلة الإعدادية. }
$$

ع - تزويد المتعلمين بمهارات استخدام التعلم عبر الويب وتتمية الاتجاه نحو هذا النوع من النالية التعلم من خلال التعامل مع بعض تطبيقات الخدمات السحابية الإلكترونية.

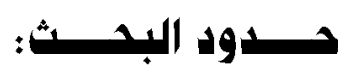

يتحدد البحث بالمحددات التالية: • عينة عشوائية من تلاميذ الصف الثالث الإعدادي.

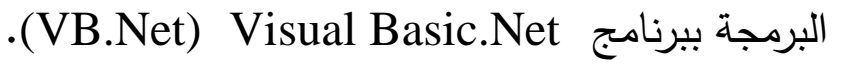

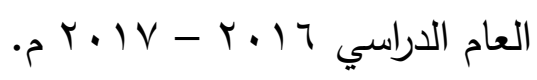

بعض تطبيقات الخدمات السحابية الإكترونية المستخدمة ( التطبيقات المكتبية لشركة جوجل ( docs- presentation) - بريـ G-Mail - السعة التخزينيـة السحابية

( Poutube مستعرض الفيديو - Forms - النماذج Prive 
تكونت عينـة البحث من (• ب) تلميذًا مقسمين إلى مجموعتين؛ المجموعـة الضـابطة

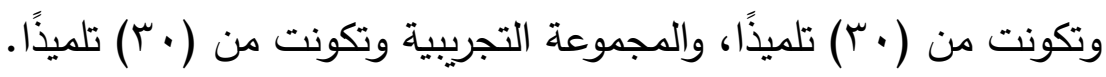

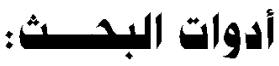

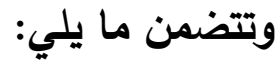

1- إختبار تحصيلى لقياس الجوانب المعرفية لمهارات البرمجة بلغة الفيجوال بيزك. r- بطاقة ملاحظة لقياس الجوانب الأدائية لمهارات البرمجة بلغة الفيجوال بيزك. منهــ ج البدث:

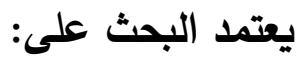
أ) المنهج الوصفي التحليلي

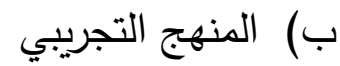
متغيرات البحـث: اثتمل البحث على المتغيرات التالية: • المتغير المستقل: برمجية قائمة على بعض التطبيقات السحابية.

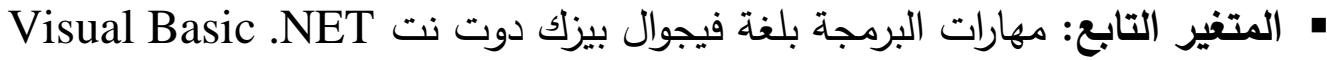

\section{فــروض البحـث:}

يحاول البحث التالي التحقق من صحة الفروض التالية:

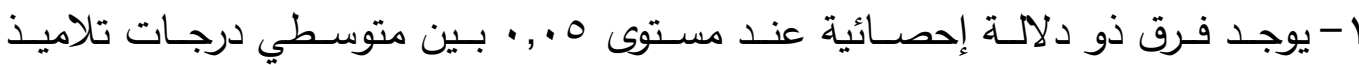

المجموعتين التجريبية والضابطة في التطبيق البعدي للاختبار التحصيلي لصالح تلاميذ

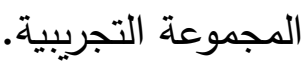

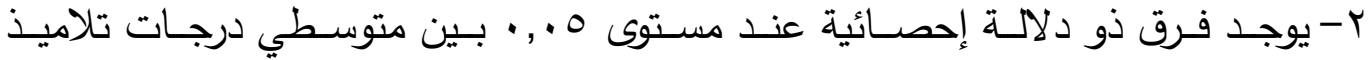

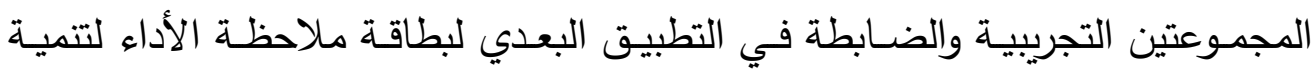
مهارات البرمجة بلغة فيجوال بيزك لصالح تلاميذ المجموعة التجريبية. ب-توجد فاعليـة للبرمجيـة القائمـة على بعض التطبيقـات السـحابية على تتميـة مهارات البرمجة بلغة الفيجوال بيزك في الاختبار التحصيلي لاى تلاميذ المرحلة الإعدادية. 
ع - توجد فاعلية للبرمجية القائمة على بعض التطبيقات السحابية في تتمية مهارات البرمجة بلغة الفيجوال بيزك في بطاقة ملاحظة الأداء لدى تلاميذ المرحلة الإعدادية.

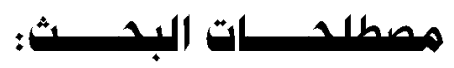

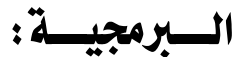

ويعرفها الباحث إجرائيًا بأنها: تنظيم لأنثطة محتوى برمجي بشكل منطقيّ ومترابط في واجهة رسومية تم بناؤها بواسطة تطبيقات سحابية، تتيح لمستخدمها التفاعل مـع محتوياتها للمساعدة في تتمية مهارات البرمجة المقررة على تلاميذ المرحلة الإعدادية.

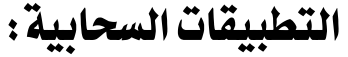

ويعرفها الباحث إجرائيًا بأنها: حلول مبنية عبر الإنترنت لاستخدامها في أي وقت وفي أي مكان لتسهيل التفاعل في عمليتي التعليم والتعلم، من أجل الوصول لتتمية مهارات البرمجة المقررة على التلاميذ بالمرحلة الإعدادية.

\section{مهارات البرمجة:}

يعرفهـا الباحـث إجرائيـا بأنهـا: متطلبـات تصـميم برمجيـة باسـتخدام فيجـوال بيـزك

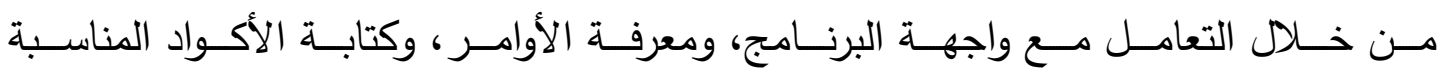
والصحيحة، لإدراك عملية الإنتاج.

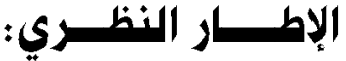

\section{ا- مميزات البرمجية التعليمية:}

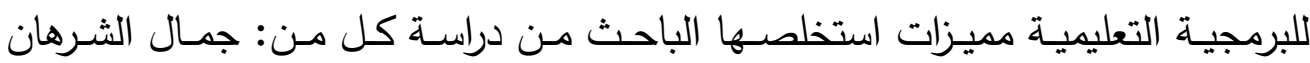

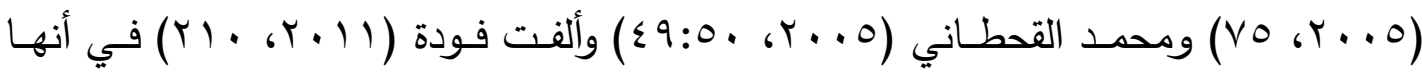
تعطي الحريـة للمتعلم في اختيار طريقة التعلم، وتتوع عرض المعلومات مع تتنظيمها ومراعاة الفروق الفردية، وتشرك أكثر من حاسة في التعلم، وتعالج الخجل، والمعلم يكرر الدرس وقت الحاجة له، وقد استفاد الباحث من مميزات البرمجية التعليمية لتحقيق فعالية البرمجية التعليمية في التدري؛ وكسر حاجز الخوف من التعامل مع البرمجيات، وتوفير الوقت للتوجيه، وتقريب المفاهيم وزيادة التحصيل، وتوفير تكاليف تدريب المتعلمين. 


\section{r- معايير تصميم البرمجيات التعليمية:}

إن إنتاج برمجية لابد من مراعاة معايير تصميم البرمجيات كما تراها إيمان المضيان

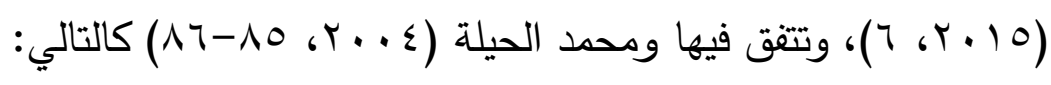

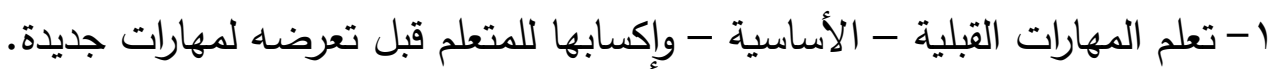
r- تنوع الأمثلة وكفاياتها بحيث يكون عددها كاف للإيضاح. r- عدرج الامثلة من السهل إلى الصعب.

ع - التفاعلية بين المتعلم ومحتويات البرمجية التعليمية. 0- تتوع عملية العرض لتغطية جوانب المادة العلمية. 1-سرعة تقديم التغذية الراجعة بعد استجابة المتعلم.

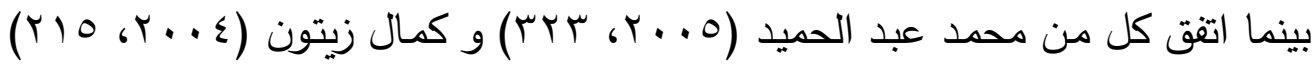

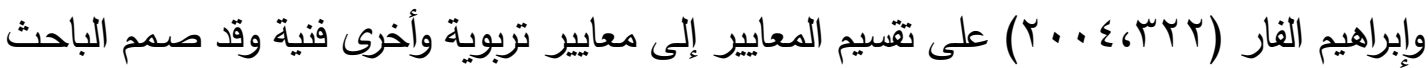

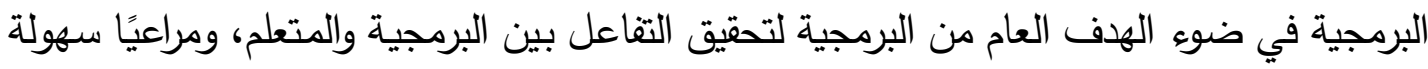
الدخول للبرمجية والخروج منها، والتتوع في العرض، والتتوع في الخطوط والألوان.

\section{ب- - أهمية البرمجية التعليمية ؛}

تمثل البرمجيات التعليمية أهمية خاصة فى العملية التربوية وذلك لما تحققة من وظائف تعليمية فى تتمية الجانبين المعرفي والأدائي فى مختلف المواد الدراسية, وقد اتفق (وائل فريد،

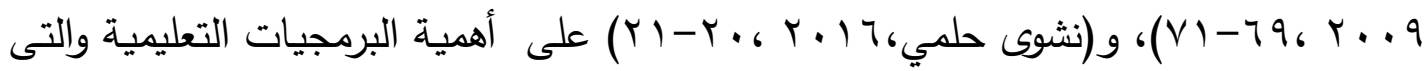

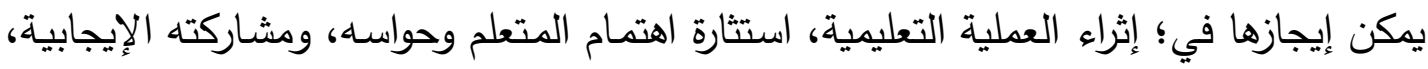

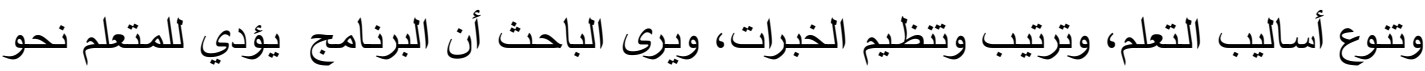

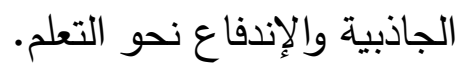

\section{؟- تصميـــم البرمجيــة:}

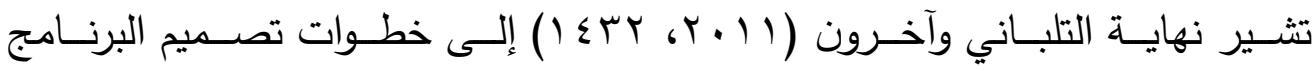

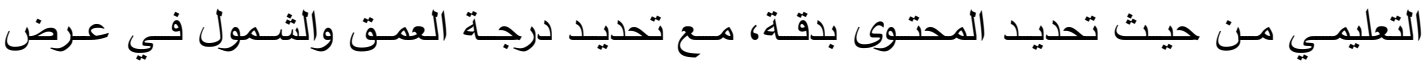

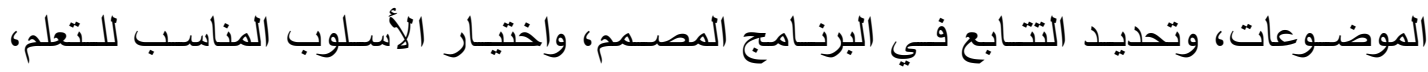
مع توفير مستلزمات البرنامج. 
وقد اسـتفاد الباحث مـن تلك الخطـوات عند تصـميمه للبرمجيـة القائمسة على بعض التطبيقات السحابية في تتمية مهارات البرمجة بلغة الفيجوال بيزك بمراعاة الآتي:

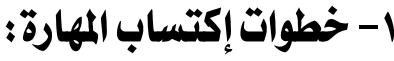

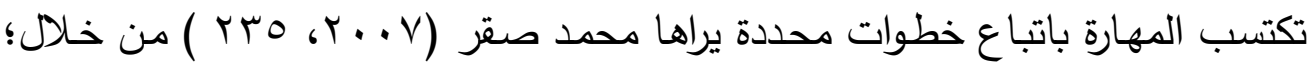

(شرح المهارة، وملاحظة المتعلم لأدائها بواسطة شخص آخر، وممارسـة المهارة تحت اشراف وتوجيه، والدقة وفي الأداء). ويفيد ذلك في مهارات البرمجة بأن يلاحظ المتعلم شرح المهارة من البرمجية القائمة على التطبيقات السحابية ثم تطبيقها وملاحظة نتائج عملية البرمجة.

\section{r- أهداف البرمجة بإستخلام فيجوال بيزك :}

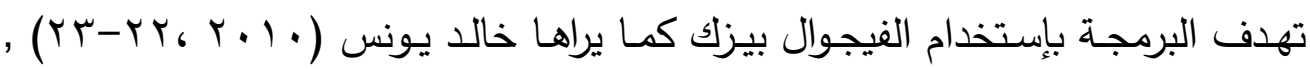

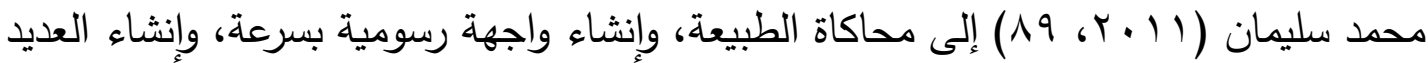
من التطبيقات.

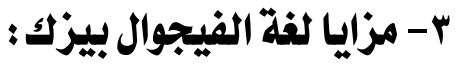

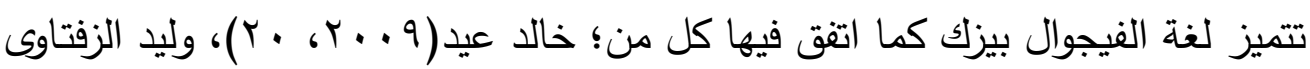

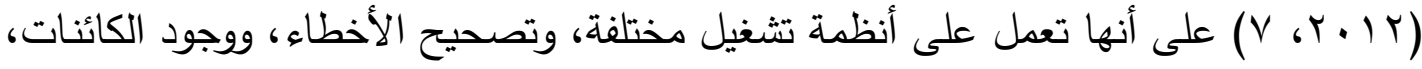
وسهولة التعديل والتطوير ، و اكتشاف الأخطاء وتصديحها، وربطها بتطبيقات أخرى، والقدرة على التعامل مع الوسائط المتعددة والصور ـ كما أنها لغة برمجة سهلة وقويـة حيث يمكن من خلالهـا كتابـة بـرامج عاليـة المستوى فى وقت أقصـر مـن اللغـات الأخـرى، فهي لغـة تصـلح

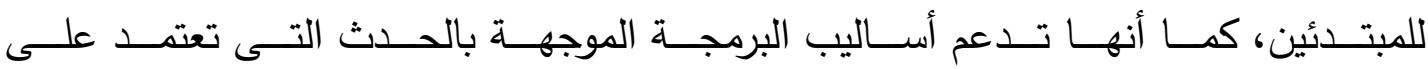
التصنيفات (Classes) والكائنات (Objects).

\section{ع- خصائص لفة الفيجوال بيزك :}

لغة البرمجة هي بالأساس طريقة تسهل للمبرمج كتابة تعليمات البرنامج التي تتفذ العمل المطلوب منها، ولكتابة التعليمات تقوم لغة البرمجة المختارة بتوفير مجموعة من الكائنات، والخصائص لكل كائن، ولكل خاصية قيمة، ومجموعة من القواعد التي تمكن من التعامل مـع أدوات البرنامج لتتكامل معًا في التعامل مع البيانات وسهولة في التصميم. 


\section{ثانيًا : التطبيقات السحابية : Cloud software}

إن التطبيقـات السـحابية أحـد أنـواع الخـدمات السـحابية المبينـة على تقنيـة الحوسـبة السحابية، وهي من أهم التطبيقات فى الوقت الحالى حيث يراها أحمد أبو سعدة (Y I إ) على أنها نموذج يقوم بتقديم البيانات والتطبيقات فى صورة خدمات عبر الشبكة العنكبوتية تمتاز بالذاتيـة والمرونـة، كمـا توفر خدمـة فى اختيـار المناسب منهـا لكل مؤسسـة تعليميـة قد تكون مدرسة أو جامعة، وتعتبر من أفضل الحلول للمؤسسات التعليمية.

\section{1- أنواع الفدمات السوابية:}

تتقسم خدمات تقنية الحوسبة السحابية على نطاق واسع إلى ثلاث فئات هي:

ا- البنية التحتية كخدمة Infrastructure as a Service وتختصر بالرمز (Iaas)

ץ- المنصة كخدمة Platform as a Service وتعرف اختصارا بالرمز (Paas).

r- البرمجيات كخدمة Software as a service وتعرف اختصارا بالرمز (Saas). وتتكون العديد من الخدمات السحابية من نوعين أو أكثر من هذه الخدمات، فالشركات الكبـرى مثل جوجل ومايكروسـوفت تمتلك الأنـواع الثلاثـة، وقـد اسـتخدم الباحـث التطبيقـات السحابية المبينة على البرمجيات كخدمة لبناء البرنامج القائم على التطبيقات السحابية، ويعتبر

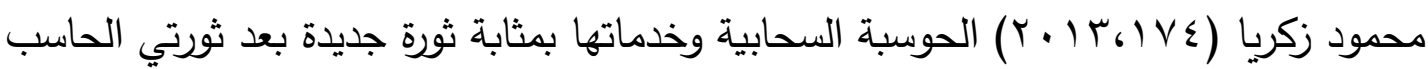
الآلي وشبكة الإنترنت، وتوصلت دراسة محمد سلمان (T ( • Y) إلى فاعلية برنامج تدريبى قائم

على تطبيقات الحوسبة السحابية فى تتمية مهارات التعلم النقال لمعلمى الحاسب الآلى.

\section{ب - فصائمر النطبيقات السهابية:}

إن التطبيقات السحابية توصف بأنها تكنولوجيا المستقبل فى مجال التعليم الإكتروني،

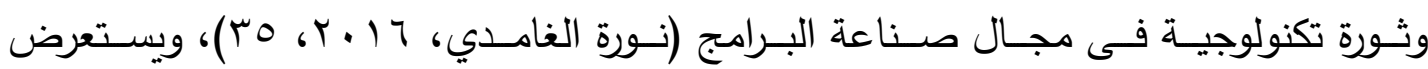
(Miller,2008:14-15)

1- التمركز حول المستخدم: فعندما يتصل المستخدم بالسحابة يستطيع المشاركة. ץ-ذات مهمة مركزية: أي ينصبّ التركيز على ما يحتاج المستخدم القيام به. ب- تمتاز بالقوة: لأنها تربط الملايين من أجهزة الحاسب الآلي معًا فى السحابة. ع - إمكانية الوصول إليها: حيث يتم تخزين البيانات واستردادها فى السحابة. 
0- الأكاء: الوصول للمعلومات المطلوبة واستخراجها وتحليلها بطربقة ذكية برغم اختلاف

وتعدد أجهزة الحاسب الآلي المتصلة بالسحابة.

צ- مبرمجة: آلية المهام؛ تسمح بحماية وتتظيم وتخزين ونقل المعلومات.

\section{"1 - فوائد التنطبيقات السحاببة:}

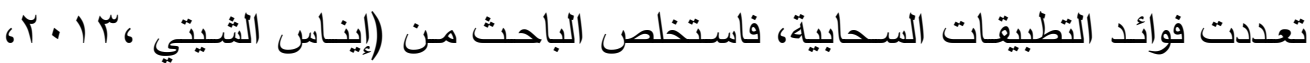

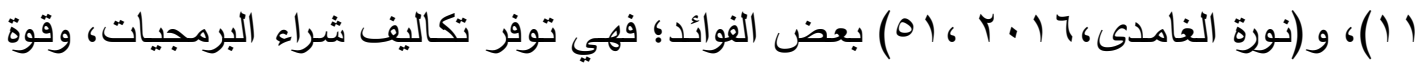
خوادم الثبكة، واستمرارية العمل، وإجراء الاختبارات مباشرة، وإدارة مشروعات التعلم.

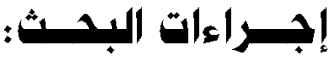

لتحقيق أهداف البحث قام الباحث بإعداد أدوات ومواد البحث التالية:

ا - قائمة مهارات البرمجة بلفة الفيجوال بيزكت.

بعد الإطـلاع على الدراسـات السـابقة والأدبيات المتصلة بهذه الدراسـة تم إعداد قائمسة مهارات لغة الفيجوال بيزك لاى تلاميذ المرحلة الإعدادية، حيث تم تحديد المهارات المقررة، وتم عرضها على مجموعة من المحكمين والمختصين في مجال تكنولوجيا المعلومات، والبرمجة، والمنـاهج وطرق التدري، وأسفرت عمليـة التحكيم عن إجـراء بعض التعديلات في صسياغة المهارات الفرعية.

\section{r- اختبار تشخيصى لمهارات البرمجة بلغة الفيجوال بيزلك.}

تم بناء مفردات الاختبار التشخيصى لقياس الأهداف السلوكية وتم صياغة الاختبار في

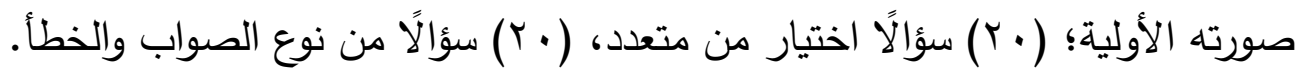
وبذلك تم تحديد المهارات الأساسية الواجب تتميتها لدى تلاميذ المرحلة الإعدادية.

\section{ب- البرمجية القائمة على بعض التطبيقات السحابية ؛}

بعد الإطلاع على الأدبيات والدراسـات السـابقة والمراجع العلمية تم تحديد الهدف من البرمجيـة؛ وهو التعبير عن النتيجـة النهائية لعمليـة التعلم والنـواتج المـراد تحقيقها مـن خـلال استخدام برمجية قائمسة على بعض التطبيقات السحابية لتنمية مهارات البرمجة بلغـة الفيجوال بيزك لدى تلاميذ المرحلة الإعدادية، ومن ثم تم إعداد المحتوى العلمي مراعيا الفروق الفردية بين التلاميذ، والتسلسل في الدروس، والتدرج من الأسهل للأصعب وتقويم ومراجعة المحتوى مع 
مراعـاة تحقيق الأهداف، ثـم عرضــه على مجموعـة مـن المحكمين المختصـين في مجـال

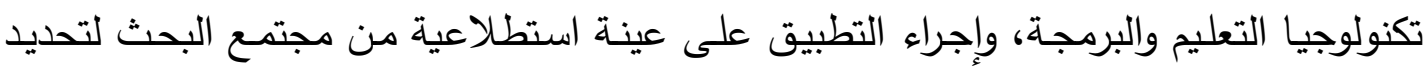
نقاط القوة وتعزيزها، ونقاط الضعف وعلاجها.

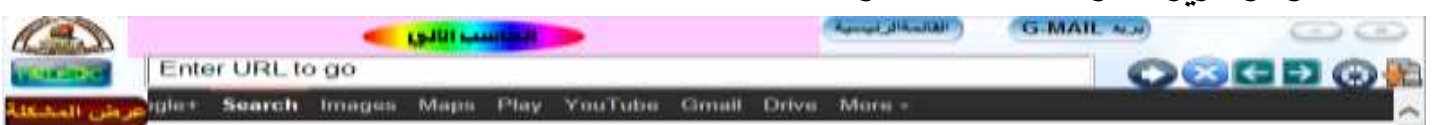
$\cos 20$

\section{شكل (1) واجهة المستخلم}

وبذلك يكون قد تم إعداد البرمجية القائمـة على بعض التطبيقيقات السحابية لتتميـة مهارات البرمجة لدى تلاميذ المرحلة الإعدادية.

\section{؟- الاختبار التحصيلى لقياس الجوانب المعرفية لمهارات البرمجة}

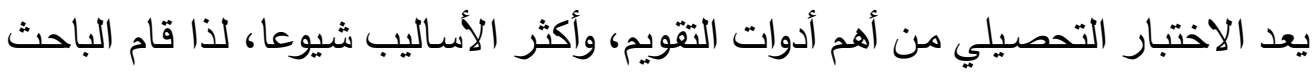

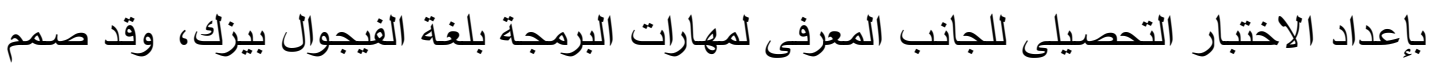

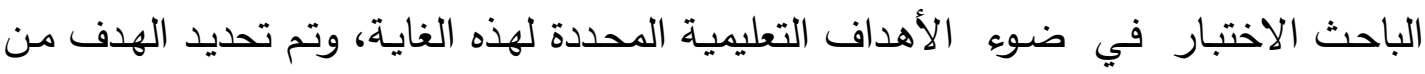

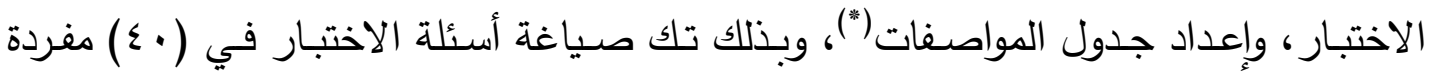

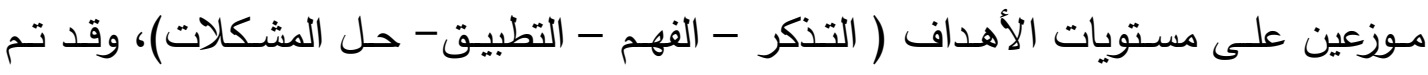

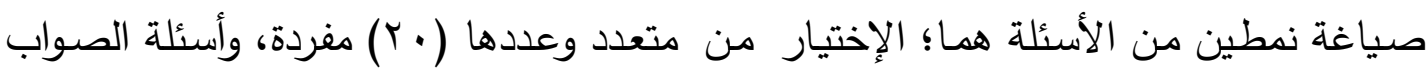

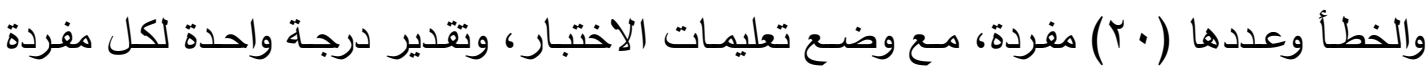

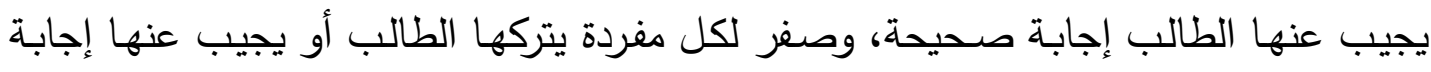

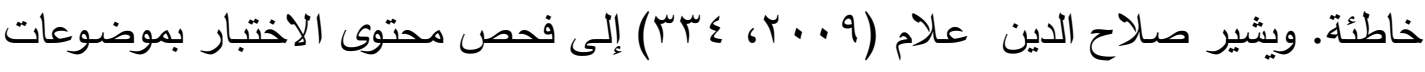
التعلم للتعرف على مدى تطابقها وخضـوعه للتحليل الاحصـائي، ومـن ثم تجربـة الاختبار 
التحصيلي على العينة الاستطلاعية حيث بلغ متوسط زمن تطبيق الاختبار (• ) دقيقة،، وكان

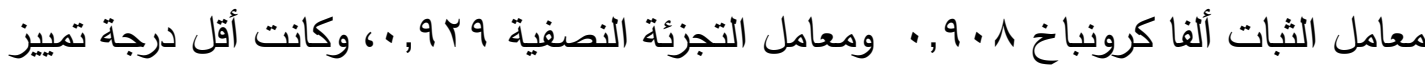

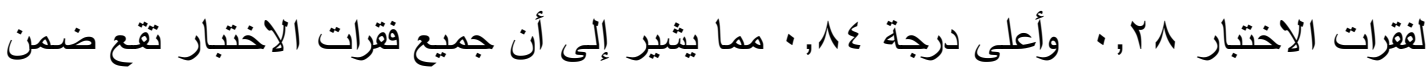

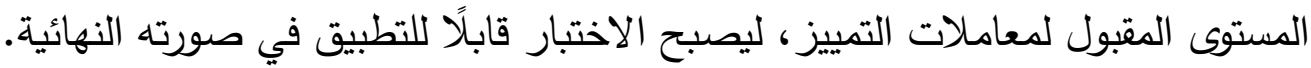

\section{ه- بطاقة ملاحظة الأداء لقياس الجوانب الأدائية لمهارات البرمجة.}

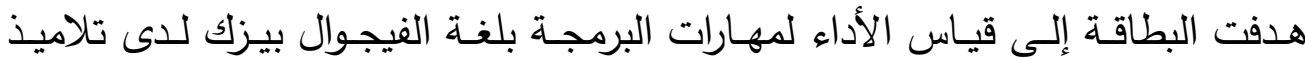
المرحلة الإعدادية، وتم اعداد تعليمات بطاقة الملاحظة وتجهيز بطاقة الملاحظة في صورتها

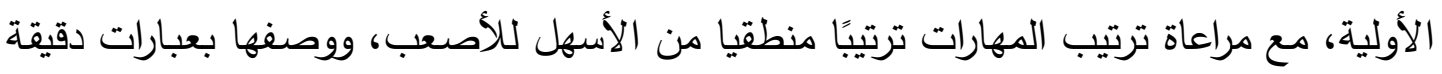

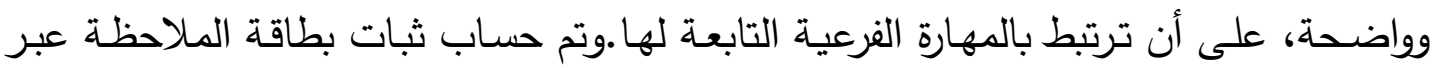

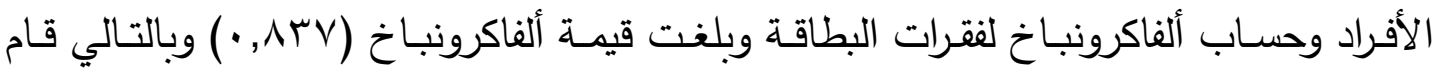

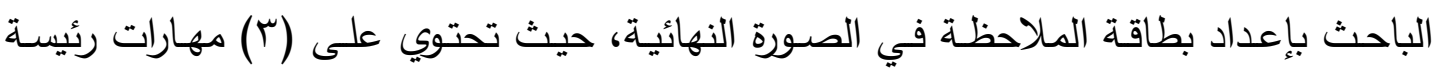

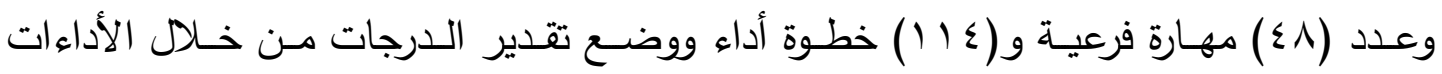

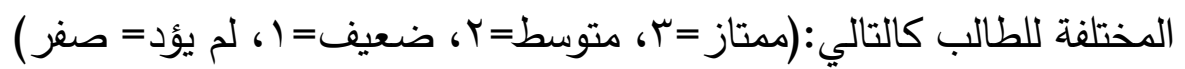

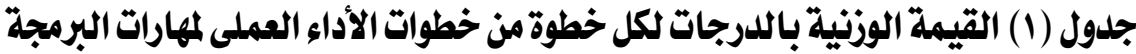

\begin{tabular}{|c|c|c|c|}
\hline القيمة الوزنية بالدرجات & علد خطوات الأداء & عدد المهارات & المشكلة \\
\hline $11 \varepsilon$ & $r \wedge$ & 10 & الأولى \\
\hline $1 \times 9$ & $\{r$ & 11 & الثانية \\
\hline $1 . r$ & $\psi \xi$ & 10 & الثالثة \\
\hline TEY & $11 \varepsilon$ & $\leqslant 1$ & المججموع \\
\hline
\end{tabular}

وبذلك تم إعداد بطاقة الملاحظة في صورتها النهائية. إجراءات تطبيق البحث:

وقام الباحث باتباع الخطوات التالية: تطبيق الاختبار التحصيلي وبطاقة الملاحظة على عينة البحالة البحث تطبيقًا قبليًا، لكي نثبت تجانس المجموعتين؛ التجريبية والضابطة. ب) تطبيق البرمجية القائمـة على بعض تطبيقات الخدمات السحابية الإلكترونية لطلاب المجموعة التجريبية، وتدرس المجموعة الضابطة بالطريقة التقليدية.

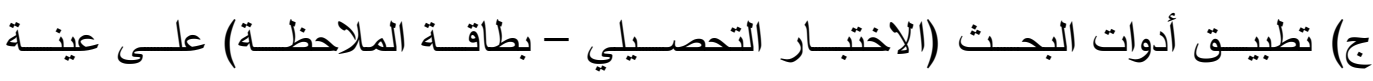
البحث تطبيقًا بعديًا. 


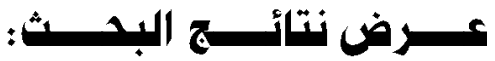

1- اختبار صحة الفرض الأول من فروض البحث ونصسه: يوجد فرق ذو دلالة إحصائية عند

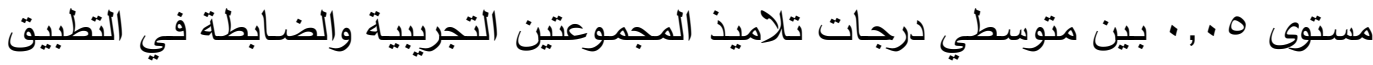
البعدي للاختبار التحصيلي لصـالح تلاميذ المجموعة التجريبية.، استخدم الباحث إختبار

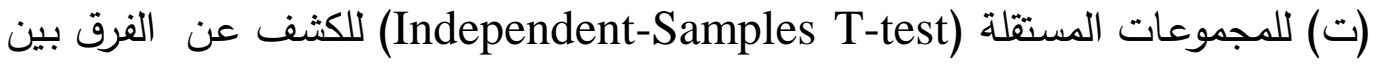

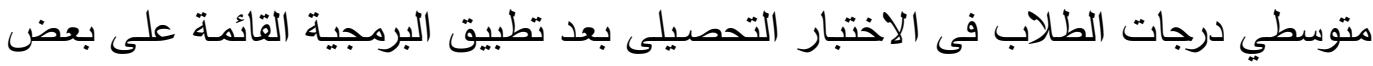
التطبيقات السحابية للمجموعة التجريبية، ودرجات طلاب المجموعة الضابطة والتى تعلىت

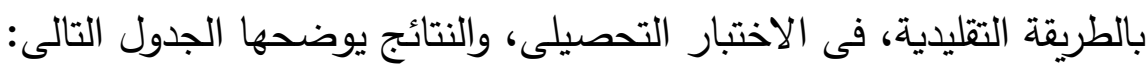

جدول ( r) قيمة اختبار ” " للفرق بين متوسطى درجات طلاب المجموعتين التجريبية والضابطة فى التطبيق البعلى للإختبار التحصيلى مع بيان حجم التأثير

\begin{tabular}{|c|c|c|c|c|c|c|c|c|}
\hline قيمة d & $\eta 2$ & الدرجية & الدلالؤ & $\begin{array}{l}\text { (تيمة } \\
\end{array}$ & الابلحراف & المتوسط & المجموعة & الأهداف \\
\hline \multirow{2}{*}{$r, \wedge 97$} & \multirow{2}{*}{ •, Y91 } & \multirow{2}{*}{$\Delta \Lambda$} & \multirow{2}{*}{$\cdot, \cdot 0$} & \multirow{2}{*}{$\mid \xi, A T \wedge$} & •, v91 & $0,1 v$ & ضابطة & \multirow{2}{*}{ تذكر } \\
\hline & & & & & •,orl & $r, v r$ & تجريبية & \\
\hline \multirow{2}{*}{ r, T\&\& } & \multirow{2}{*}{ •, $\vee 71$} & \multirow{2}{*}{$\Delta \wedge$} & \multirow{2}{*}{$\cdot, 0$} & \multirow{2}{*}{$1 \%, A \vee q$} & $1,1 \wedge \varepsilon$ & $7, T V$ & ضابطة & \multirow{2}{*}{ فهـ } \\
\hline & & & & & $\cdot, \vee \wedge \wedge$ & $1 \cdot, r Y$ & تجريبية & \\
\hline \multirow{2}{*}{ r,AOT } & \multirow{2}{*}{ •, Tr. } & \multirow{2}{*}{01} & \multirow{2}{*}{$\cdot, \cdot 0$} & \multirow{2}{*}{$1 \cdot, \wedge 71$} & $1, \cdot 10$ & $\xi, q \mu$ & ضابطة & \multirow{2}{*}{ مهارات } \\
\hline & & & & & , VYY & $r, \& v$ & تجريبية & \\
\hline \multirow{2}{*}{$\xi, \cdot r \xi 0$} & \multirow{2}{*}{$\cdot, A \cdot 1$} & \multirow{2}{*}{01} & \multirow{2}{*}{$\cdot, \cdot 0$} & \multirow{2}{*}{10, TrO } & $\cdot, 9 \cdot \cdot$ & $\Lambda, I T$ & ضابطة & \multirow{2}{*}{ حل مشكلات } \\
\hline & & & & & $1, \cdot+r$ & $11,9 \mathrm{qr}$ & تجريبية & \\
\hline \multirow{2}{*}{$0, \$ 90$} & \multirow{2}{*}{ - AAT } & \multirow{2}{*}{$\Delta 1$} & \multirow{2}{*}{ •, } & \multirow{2}{*}{ re,qrY } & $\overline{r, \gamma \wedge \xi}$ & $r \xi, q$. & ضابطة & \multirow{2}{*}{ الإختبار الكلى } \\
\hline & & & & & $1, \mathrm{VFM}$ & $r Y, \xi T$ & تجريبية & \\
\hline
\end{tabular}

يتضـح مـن الجدول السـابق وجود فرق دال إحصـائًا بين متوسطي درجات طـلاب

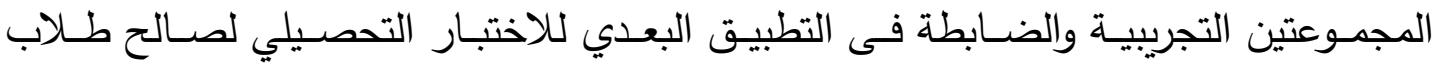

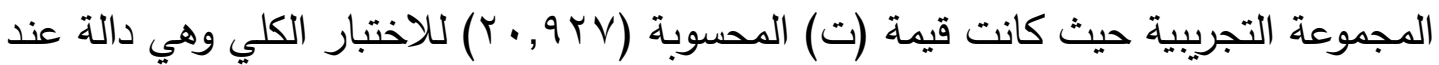

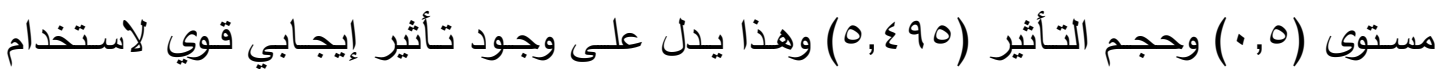
التطبيقات السحابية في زيادة التحصيل المعرفي المرتبط بمهارات البرمجة لاى تلاميذ المرحلة الإعدادية، وبذلك تم قبول الفرض الأول. r- اختبار صحة الفرض الثاني ونصه: يوجد فرق ذو دلالة إحصائية عند مستوى 0 ., · بين متوسطي درجـات طـلاب المجموعتين التجريبيـة والضــابطة في التطبيق البعدي لبطاقـة 
ملاحظــة الأداء لتتميـة مهـارات البرمجـة بلغــة فيجـوال بيـزلك لصـالح طـلاب المجموعـة التجريبية، واستخدم الباحث إختبار (ت) للمجموعات المستقلة (Independent-Samples (T-test البرمجية القائمة على التطبيقات السحابية لمجموعة التجريبية، ودرجات طلاب المجموعة الضـابطة والتى تعلمت بالطريقة التقليدية، والنتائج يوضحها الجدول التالى: جدول ( ץ ) قيمة اختبار ”ت ” للفرق بين متوسطى درجات طلاب المجموعتين التجريبية والضابطة فى التطبيق البعدى لبطاقة ملاحظة الأداء مع بيان حجم التأثير

\begin{tabular}{|c|c|c|c|c|c|c|c|c|}
\hline قيمة d & $\eta 2$ & الحرية & مستوى & قيمة (ت) & الالميارى & المتوسط & المجموعة & الرئيسية \\
\hline \multirow{2}{*}{7, Y } & \multirow{2}{*}{$\cdot, q \cdot v$} & \multirow{2}{*}{01} & \multirow{2}{*}{$\cdot, \cdot 0$} & \multirow{2}{*}{$r r, \wedge O \xi$} & $r, \wedge 0 q$ & $\wedge \varepsilon, \bullet \vee$ & ضابطة & \multirow{2}{*}{ المهارة الأولى } \\
\hline & & & & & $r, 1 \xi$. & $1 \cdot 0, r r$ & تجريبية & \\
\hline \multirow{2}{*}{ r, TYo } & \multirow{2}{*}{ •, rru } & \multirow{2}{*}{01} & \multirow{2}{*}{$\cdot, \cdot 0 \square$} & \multirow{2}{*}{17,997} & r, ২৭\& & $q \Lambda, \vee \vee$ & ضابطة & \multirow{2}{*}{ المهارة الثانية } \\
\hline & & & & & $r, I T Y$ & $119, \xi$ & تجريبية & \\
\hline \multirow{2}{*}{$r, \cdot 9}$. & \multirow{2}{*}{$\cdot, r \cdot \xi$} & \multirow{2}{*}{01} & \multirow{2}{*}{$\bullet, \cdot 0 \square$} & \multirow{2}{*}{$11, \vee 79$} & $\xi, \vee r q$ & $\wedge \vee, \xi_{\bullet}$ & ضابطة & \multirow{2}{*}{ المهارة الثالثة } \\
\hline & & & & & r, TAr & $99,1$. & تجريبية & \\
\hline \multirow{2}{*}{ v, ro } & \multirow{2}{*}{ •,9ro } & \multirow{2}{*}{10} & \multirow{2}{*}{$\cdot, \cdot 0 \square$} & \multirow{2}{*}{ rq, Yor } & $v, \bullet \xi \cdot$ & $r V \cdot, r r$ & ضابطة & \multirow{2}{*}{ الإجمالي } \\
\hline & & & & & ^,OYO & rYS,Yr & تجريبية & \\
\hline
\end{tabular}

يتضــح مـن الجـدول الســابق وجـود فـرق دال إحصــائيًا بــين متوسـطي درجـات

طـلاب المجمـوعتين التجربيــة والضــابطة فـى التطبيـق البعـدي لبطاقــة ملاحظـــة الأداء لصــالح طــلاب المجموعــة التجريبيـة،، حيــث بلغــت قيمــة (ت) المحسـوبة (Y,VOY)

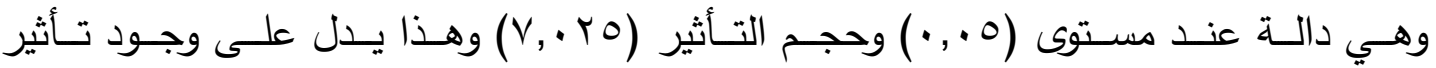
إيجابي قوي، بذلك تم قبول الفرض الثاني.

r- اختبار صحة الفرض الثالث ونصسه: توجد فاعلية للبرمجية القائمـة على بعض التطبيقات السـحابية على تتمية مهارات البرمجـة بلغـة الفيجوال بيزك في الاختبار التحصيلي لدى Paired تلاميذ المرحلة الإعدادية، واستخدم الباحث اختبار "ت" للمجموعات المرتبطـة لمعرفة دلالة الفرق بين متوسطى درجات طلاب المجموعة التجربيية فى (Sample test) التطبيقين القبلى والبعدى للإختبار التحصيلى. 
جلدول (§) قيمة اختبار "ت "للفرق بين متوسطى درجات طلاب المجموعة التجريبية

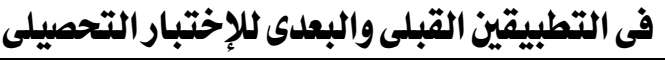

\begin{tabular}{|c|c|c|c|c|c|c|}
\hline مستوى & قيمة (ت) & الالانحراف & المتوسط & الحرية & التطبيق & الأهداف \\
\hline \multirow{2}{*}{$\cdot, \cdot 0$} & \multirow{2}{*}{$19, Y \leqslant 9$} & $1, Y Y \varepsilon$ & $r, I r$ & \multirow{2}{*}{ rq } & قبلى & \multirow{2}{*}{ تذكر } \\
\hline & & •,OrI & $v, v r$ & & بعدى ل بع & \\
\hline \multirow{2}{*}{$\cdot, \cdot 0$} & \multirow{2}{*}{09,090} & - Y^A & $\cdot, 0$. & \multirow{2}{*}{ rq } & قبلى & \multirow{2}{*}{ فهـ | فهر } \\
\hline & & •, or & $1 \cdot, r V$ & & بعدى ب بع & \\
\hline \multirow{2}{*}{$\cdot, \cdot 0$} & \multirow{2}{*}{$Y \xi, Y \cdot q$} & $\cdot, 940$ & $1, r \mu$ & \multirow{2}{*}{ rq } & قبلى & \multirow{2}{*}{ مهارات } \\
\hline & & •, VYq & $V, \xi \gamma$ & & بعلى ب بع & \\
\hline \multirow{2}{*}{$\cdot, \cdot 0$} & \multirow{2}{*}{ SY, rqY } & $\cdot$, AIV & $\cdot, V V$ & \multirow{2}{*}{ rq } & قبلى & \multirow{2}{*}{ حل المشكلات } \\
\hline & & $1, \cdot r r$ & $11,9 \mathrm{~V}$ & & بعدى ب بع & \\
\hline \multirow{2}{*}{$\bullet, \cdot 0$} & \multirow{2}{*}{$\vee 7, r \wedge I$} & 1,019 & $0,7 r$ & \multirow{2}{*}{ rq } & قبلى & \multirow{2}{*}{ لإختبار الكلى } \\
\hline & & I, Vry & $r Y, \xi T$ & & بعدى ب بع & \\
\hline
\end{tabular}

يتضح من الجدول المابق وجود فرق دال إحصائيًا بين متوسطي درجات طلاب المجموعة التجريبية فى التطبيقين القبلى و البعدى للإختبار التحصيلى حيث كانت قيمـة (ت) الدحسوبة لإنية

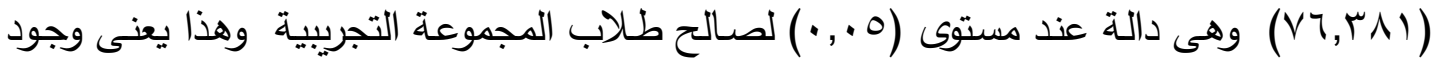
تأثير إيجابى قوى للبرمجية القائمسة على التطبييقات السحابية فى تتمية الجانب المعرفى المرتبط بمهارات البرمجة لدى الطلاب عند مستوى (0. . ) ) وبذلك تم قبول الفرض الثالث. ع - اختبار صحة الفرض الرابع ونصه: توجد فاعلية للبرمجية القائمة على بعض التطبيقات السحابية في تنمية مهارات البرمجة بلغة الفيجوال بيزك في بطاقة ملاحظة الأداء لاى

$$
\text { تلاميذ المرحلة الإعدادية. }
$$

جدول (0) قيمة اختبار " " للفرق بيز متوسطى درجات طلاب المجموعة التجريبية

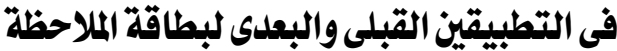

\begin{tabular}{|c|c|c|c|c|c|c|}
\hline مستوى الدلالة & قيمة (ت) & الانحر اف المعيارى & المتوسط & درجات الحرية & التطبيق & المهارات الرئيسية \\
\hline \multirow{2}{*}{$\cdot, \cdot 0$} & \multirow{2}{*}{$1 \varepsilon Y, \vee 79$} & $1, \wedge 9$ & $r, r$. & \multirow{2}{*}{ rq } & قبلى & \multirow{2}{*}{ المهارة الأولى } \\
\hline & & $r, 1 \varepsilon \cdot$ & $1 \cdot 0, V r$ & & بعدى & \\
\hline \multirow{2}{*}{$\cdot, \cdot 0$} & \multirow{2}{*}{$\wedge q, \vee v}$. & $1, \wedge \leqslant 7$ & $0,1$. & \multirow{2}{*}{ rq } & قبلى & \multirow{2}{*}{ المهارة الثانية } \\
\hline & & $Y, I Y Y$ & 119,80 & & بعدى & \\
\hline \multirow{2}{*}{$\cdot, \cdot 0$} & \multirow{2}{*}{$\mid r \varepsilon, q \cdot Y$} & $r, 077$ & $0, \mathrm{rr}$ & \multirow{2}{*}{ rq } & قبلى & \multirow{2}{*}{ المهارة الثالثة } \\
\hline & & r,Arr & $99,1$. & & بعدى & \\
\hline \multirow{2}{*}{$\cdot, \bullet$} & \multirow{2}{*}{$189,0.1$} & $r, \xi 11$ & $I r, \wedge V$ & \multirow{2}{*}{ rq } & قبلى & \multirow{2}{*}{ إجمالى المهارات } \\
\hline & & 1,oro & $r r \xi, r r$ & & بعدى & \\
\hline
\end{tabular}


وقد استخدم الباحث اختبار (ت) للمجموعات المترابطة (Paired Sample test) لمعرفة دلالة الفرق بين متوسطى درجات المجموعة التجريبية فى التطبيقين القبلى والبعدى

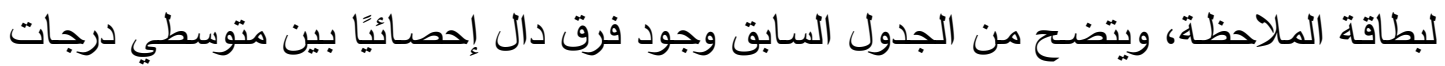

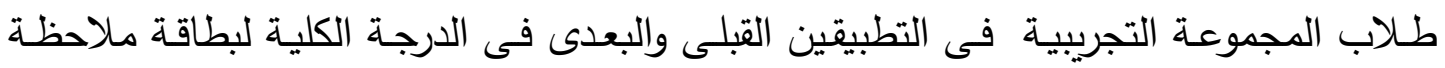

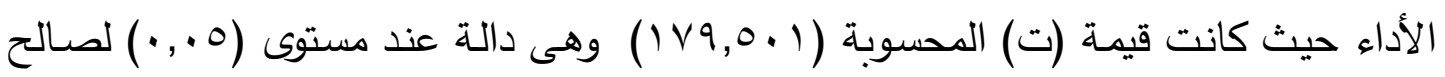
التطبيق البعدى وكذلك وجود فروق دالة احصائيا فى المهارات الأدائية وهذا يعنى وجود تأثير

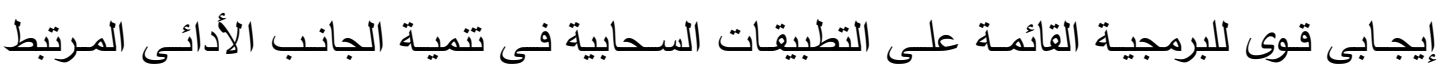

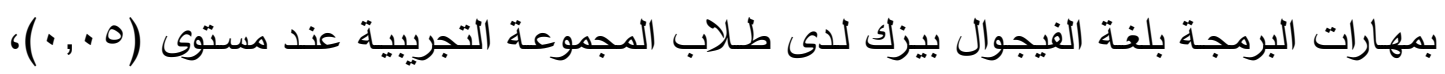
وبذلك تم قبول الفرض الرابع.

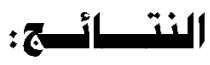

توصل البحث إلى أن التلاميذ الذين استخدموا البرمجية القائمة على بعض التطبيقات

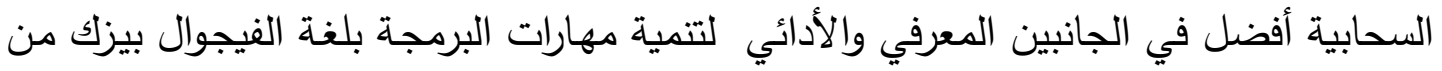

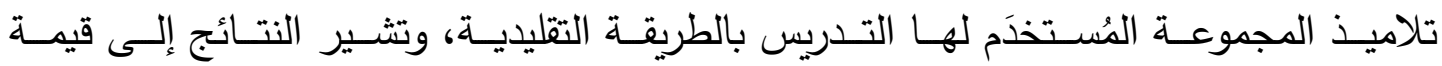

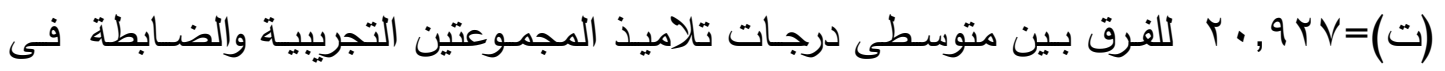

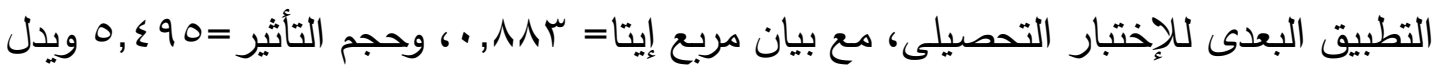

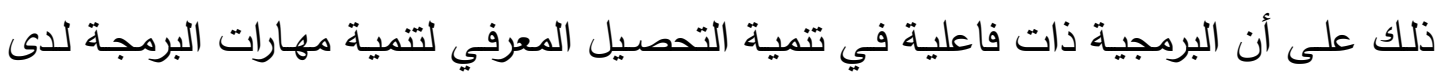

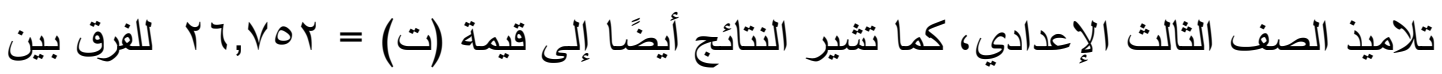

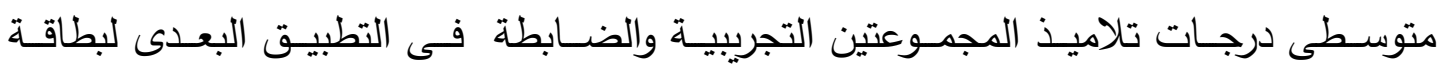

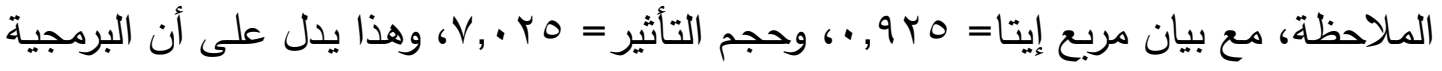

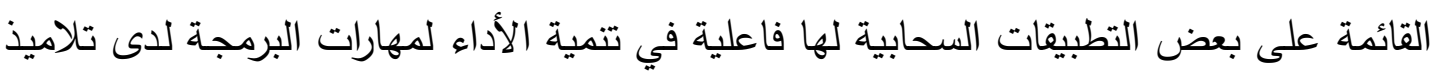

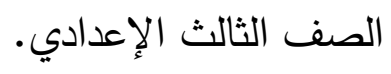

كما يمكن تفسير النتائج في ضوء الاعتبارات التالية: " تنظيم عرض المعلومات في البرمجية، وسهولة الوصول إليها.

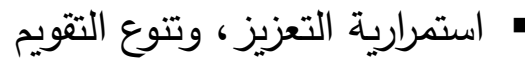

- تغيير النمط التقليدي في التدريس إلى استخدام برمجية مُستخدَم فيها التطبيقات السحابية. • اتاحة البرمجية للوقت الكافي للمارسة والتدريب. 
- التطبيقـات السـابية لديها الكفـاءة، والقدرة على تطوير وتطبيق التفكير المنطقي لحل المشكلات لاكتساب مهارات من واقع الحياة اليومية.

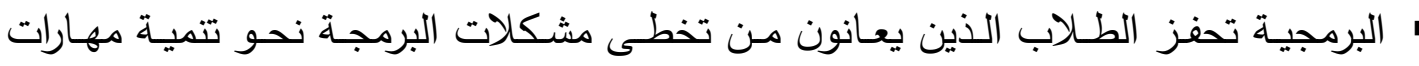
البرمجة لحل هذه المشكلات ثم إنتاج برمجيات بما يتناسب مع الدقرر الدراسي. • وجود المتصفح الخاص بالبرمجية دون اللجوء لمتصفحات من شركات أخرى. • التتوع في عرض المهارات من الأسهل للأصعب لتتمية مهارات البرمجة. • البرمجية تحفز المتعلمين نحو التعلم وتتمية المهارات اللازمة للبرمجة.

على ضوء ما أسفرت عنه نتائج البحث يوصي الباحث بما يلي: واتي

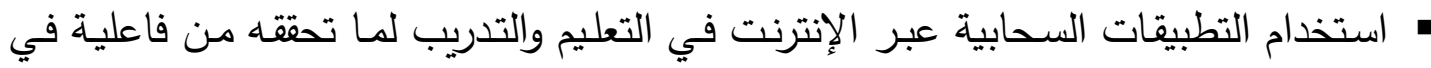
عملية التعليم والتعلم وتحسين فرص التعلم الذاتي. " الاهتمـام بتتمية مهارات البرمجة في المراحل التعلييمية خاصسة في الصنغر لبنـاء خبرات تعليمية يُبنَى عليها بعد ذلك، مما يساعد في تتمية التفكير . • نشر الوعي بأهمية البرمجة لكونها مجال عمل في المستقبل لأبنائنا.

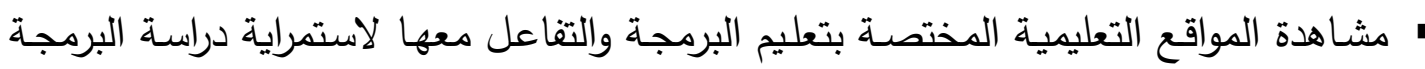
وتحديث ما تم اكتسابه من مهارات. • البرمجة للجميع دون النظر لجمود الفكر، طالما ليس لديه أي معوقات ذهنية. " عمل ورش عمل تدريبية بمراكز التدريب خارج زمن وتوقيت التدريب. عمل مجموعات للمتعلمين لتبادل الخبرات من خلال التطبيقات السحابية.

- إنتاج برمجيات قائمة على التطبيقات السحابية لمراحل تعليمية مختلفة " دراسة أثر استخدام البرمجيات التعليمية على تتمية مهارات التفكير والمهارات الرياضية. - دراسة مثابهة بالبحث الحالي لتتمية الإتجاه نحو إنتاج البرمجيات. دراسة تحليلية عن إدراك فئات مختلفي السعة العقلية لمهارات البرمجة. دراسة أثر استخدام انترنت الأشياء على تتمية مهارات البرمجة. 
1- إبراهيم أحمد السيد عطية (• • ب):"أثر التفاعل بين استراتيجية حل المشكلات مفتوحة النهاية والسعة العقلية على الحلول الإبتكارية لمشكلات البرمجة التعليمية لدى طلاب الدبلوم

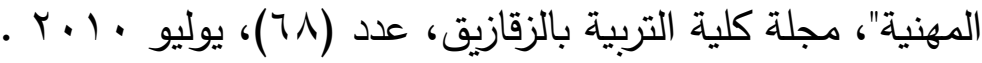

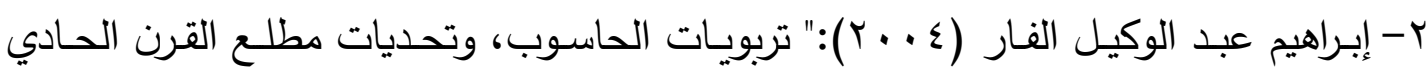

$$
\text { والعشرون"، الفكر العربي، القاهرة. }
$$

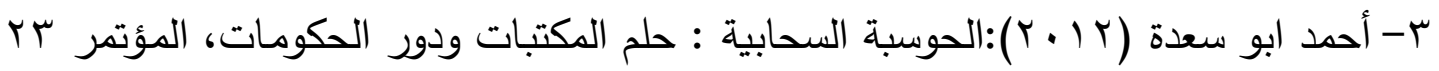

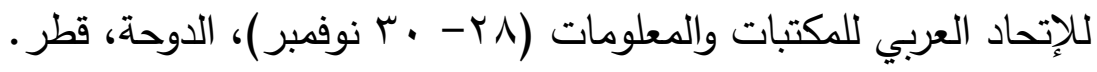

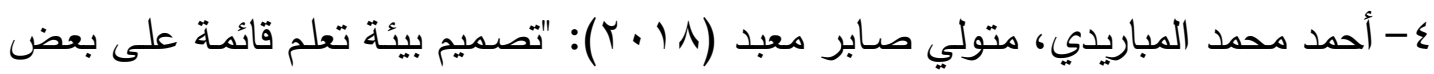

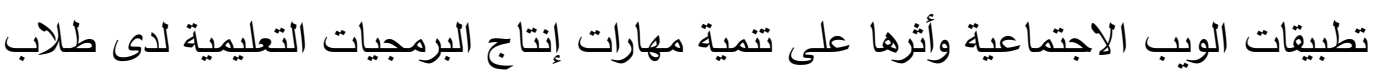

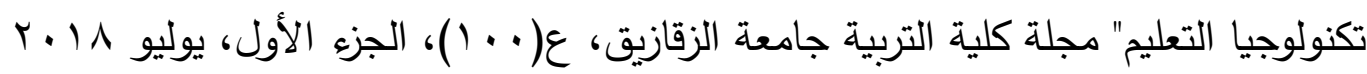

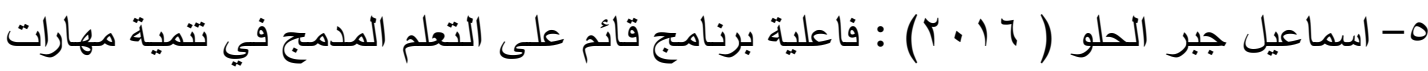

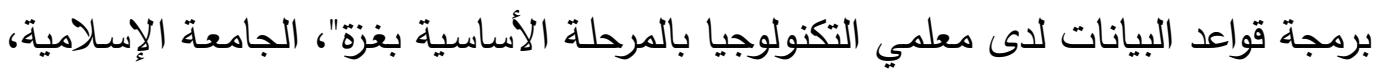
غزة، فلسطين

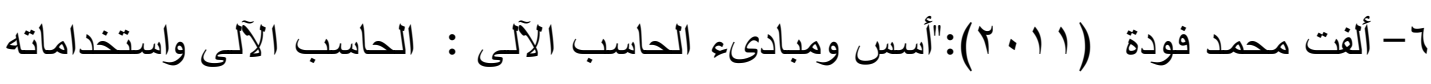
فى التعليم"، ط(ץ)، جامعة الملك سعود، كلية التربية.

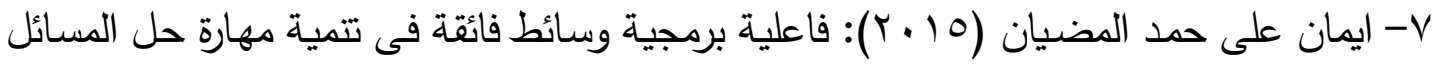

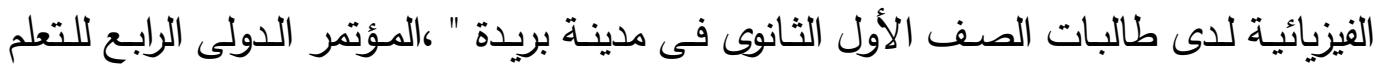

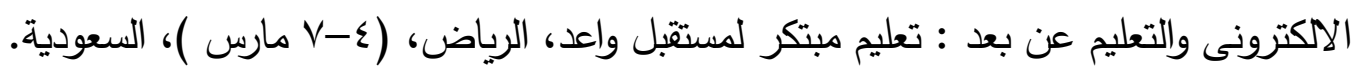

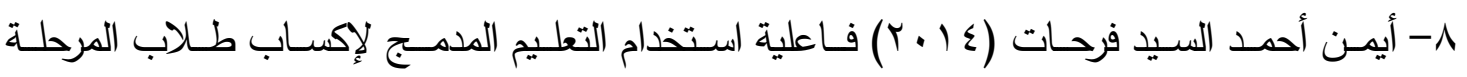

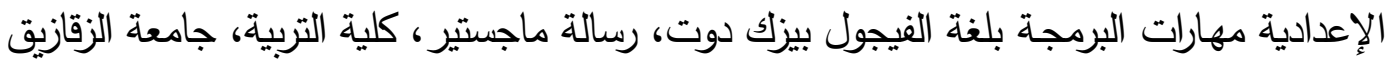

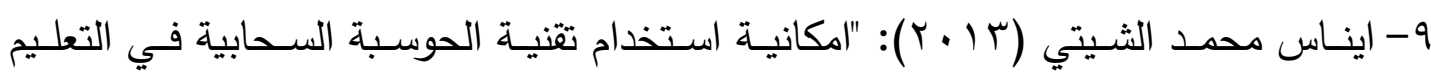
الالكتروني في جامعة القصيم"، المؤتمر الدولي الثال للتعليم الالكتروني والتعليم عن بعدة التئة

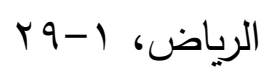

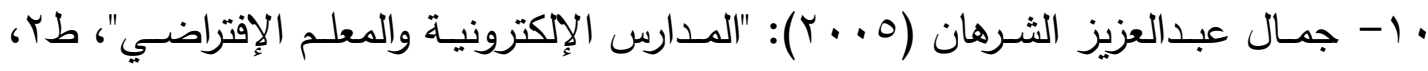
الرياض، مطابع الحميضي. 


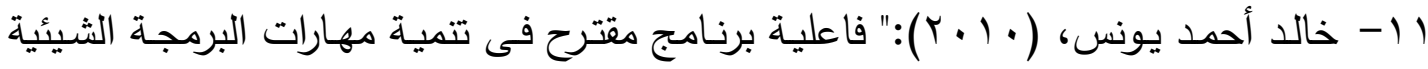

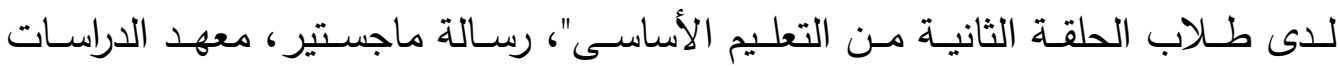

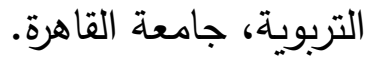

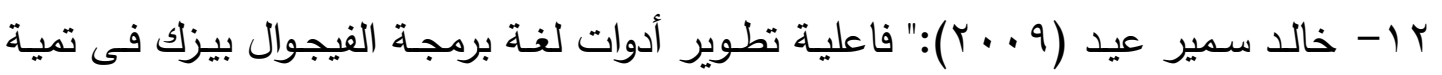
مهارات تصميم التقويم للى طلبة العلوم التطبيقية وتكنولوجيا التعليم بالجامعة الإسلامية بغزة ومدى اكتساب الطلبة بها "، رسالة ماجستير ، الجامعة الإسلامية، فلسطين.

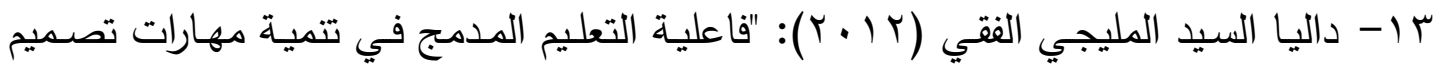
وإنتاج مشروعات ابتكارية بالبرمجة الثيئية لدى طلاب الصف الأول الثانوي وعلاقة ذلك بالدافعية للإنجاز"، رسالة ماجستير ، كلية التربية، جامعة طنطا

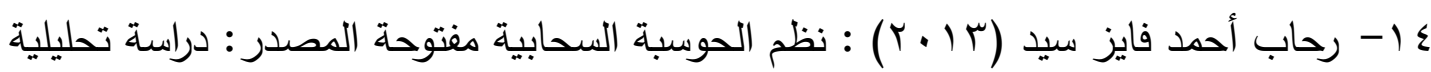
مقارنة، المجلة العراقية لتكنولوجيا المعلومات، ه (ץ)، صص 17 ا-1ـ .

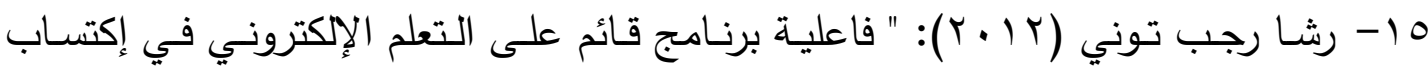
وإستخدام طلاب الصف الأول الثانوي بعض مهارات البرمجة بلغة فيجوال بيزك وتتمية الإتجاه نحوها" رسالة ماجستير ،كلية التربية،جامعة المنيا.

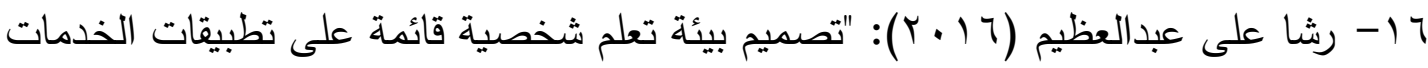
السحابية الإككترونيـة لتتمية مهارات التصميم التعليهى للى طلاب تكنولوجيا التعليم"، أطروحة ماجستير ، كلية التربية جامعة المنصورة.

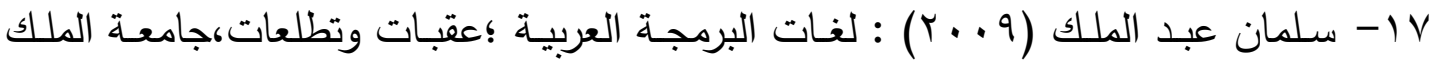
سعود، كلية علوم الحاسب والمعلومات، السعودية.

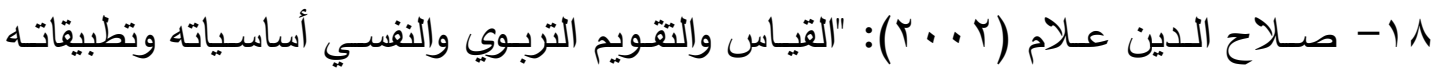
وتوجيهاته المعاصرة"، القاهرة، دار الفكر العربي.

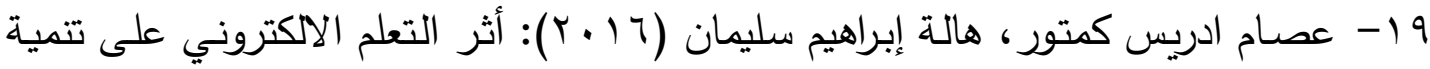

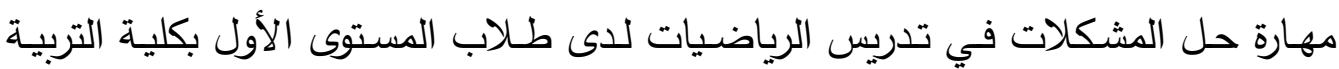

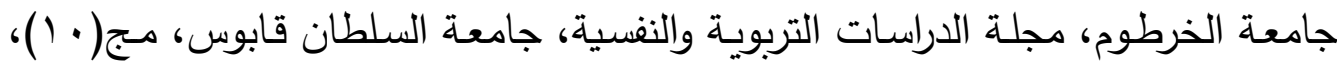

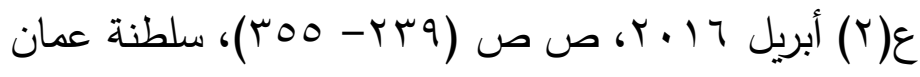




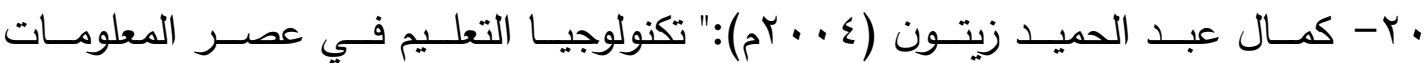
والاتصالات"، طب، عالم الكتب، القاهرة.

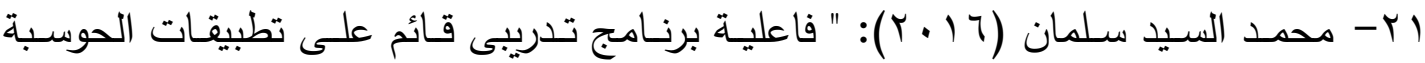
السحابية فى تتمية مهارات التعلم النقال لمعلمى الحاسب الآلى "، رسالة ماجستير غير منشورة، كلية التربية، جامعة المنصورة

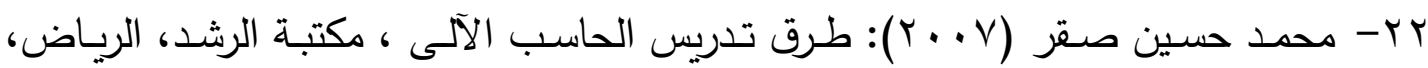
السعودية.

r - محمد عائض القحطاني (0 . r) : "أثر استخدام الإنترنت وبرمجية تعليمية موجهة على تحصيل تلاميذ المرحلـة المتوسطة للمفـاهيم في مـادة العلـوم "، رسـالة ماجستير غير منشورة، الرياض،كلية التربية جامعة الملك سعود. צ ץ- محمد عبد الحميد معوض (0 . . rم):"منظمة التعليم عبر الثبكات" عالم الكتب القاهرة.

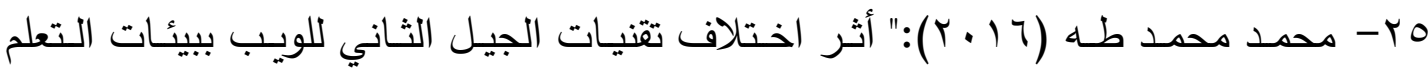
الإلكتروني التعاونيـة في اكسـاب مهارات البرمجـة لدى طـلاب المرحلـة الثانويـة"، كليـة التربية النوعية جامعة عين شمس.

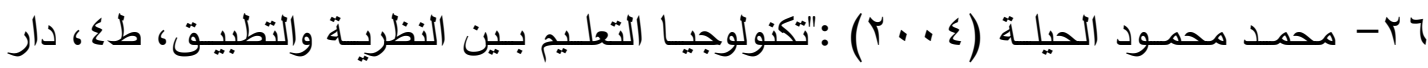
المسيرة للنشر والتوزيع ،عمان، الأردن.

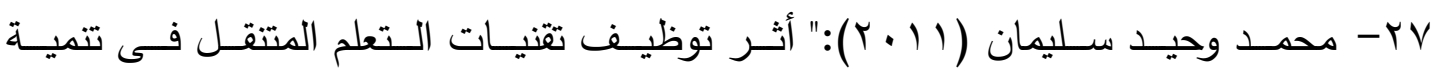
مفــاهيم البرمجــة الثـيئية لـدى طـلاب المعاهـــ الأزهريــة "، رسـالة ماجسـتير، كليـة التربية، جامعة بنها.

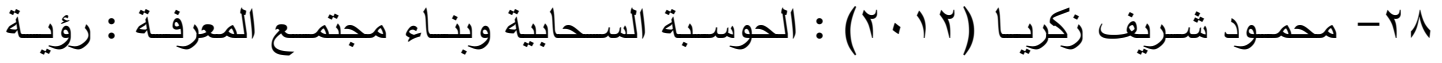
استشـرافية، المؤتمر الثالث والعشرون للإتحـاد العربى للمكتبات والمعلومـات : الحكومـة

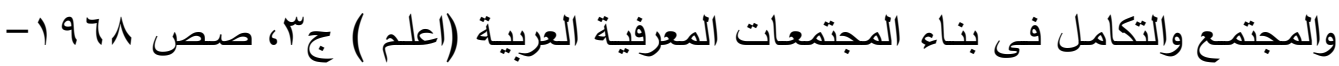

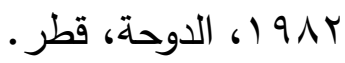

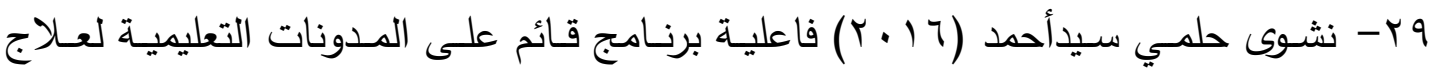
صـوبات تعلم مهارات البرمجـة (V.B) لدى طلاب المرحلة الثانويـة"، رسـالة ماجستير غير منشورة، كلية التربية، جامعة الزقازيق، مصر • 


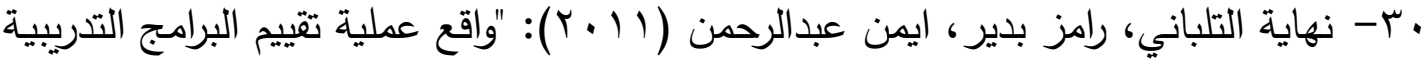
فى الهيئات المحلية بالمحافظات الجنوبية"، مجلة جامعة الأزهر ، سلسلة العلوم الإنسانية،

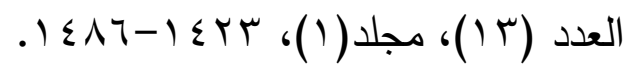

اب- نورة سعد على الغامدي (T ( • ץ): "أثر برنامج مقترح قائم على تطبيقات جوجل السحابية

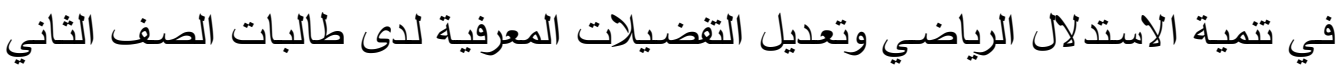
الثانوي بمحافظة جدة"، رسالة دكتوراة غير منشورة، كلية التربية، جامعة أم القرى.

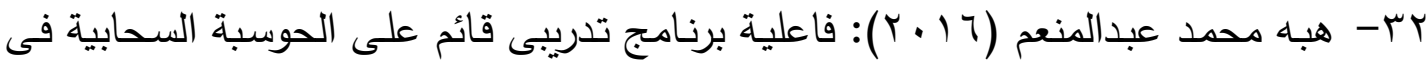
تتمية بعض المهارات المهنية لاى مسئولى وحدات تدريب المعلمين بالمرحلة الإبتدائية.

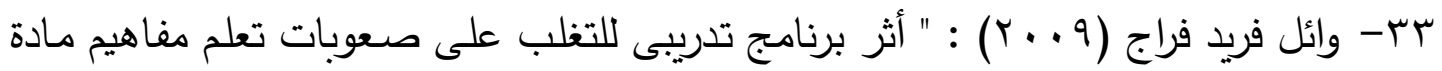

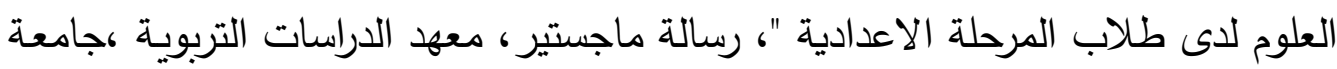

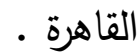

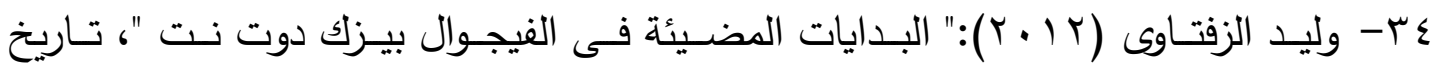

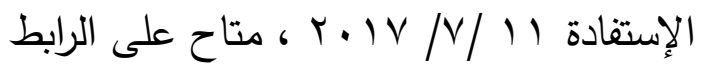
http:// www, kutub, info/library/ book/ 12075

\section{ثانيا المراجع الأجنبية: - اجي}

35- Bennedsen, J., Caspersen, M. E., \& Kölling, M. (Eds.) (2008). Reflections on the teaching of programming: methods and implementations. Berlin: Springer LNCS. Lecture Notes in Computer Science (LNCS), No. 4821

36- Iain McAlpine( 2001):PROBLEM BASED LEARNING IN THE DESIGN OF A MULTIMEDIA PROJECT, Australian Journal of Educational Technology, 2001, 17(2), 115-130

37- Garofalakis, J.,Lagiou, E.\& Plessas, A.(2013).Use of web 2.0 tools for teaching physics in secondary education. International Journal of Information and Education Technology, 3(1), 6-9 
38- Hooper, c, Carr,L.,Millard,D., and Wills, G. (2007).Tools for Teaching Programming.Jornal of computers2(5), university of Southampton,UK.

39- Kranch, D, A, (2010):" A study of three instructional sequences for developing computer programming experties in novice learners, Unpublished doctoral Dissertation.

40- Mcloughlin, C\& Lee,M (2011). Web 2.0 based e-learning applying social informatics for tertiary teaching. IGI global, 701E, 12)6, 21-42

41- Miller,M. (2008):Cloud Computing: Web-Based Applications that Change the way you Work and Collaborate Online, USA, New York pearson.

42- Michael J. Scott، Gheorghita Ghinea (2014) ،On the DomainSpecificity of Mindsets: The Relationship Between Aptitude Beliefs and Programming Practice. Published in: IEEE Transactions on Education ( Volume: 57، Issue: 3، Aug. 2014 ) Retrieved 30/10/2016 from Available at http://ieeexplore.ieee.org/document/6662493/ 


\section{ملحق (1) مانمبان}

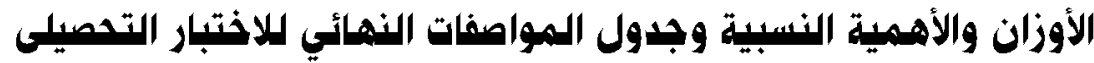

الأهمية النسبية للموضوعات (عدل الصفهات- عدل الدصص)

\begin{tabular}{|c|c|c|c|c|c|}
\hline متوسط النسبة & النسبة المئوية & علد الحصص & المئوية & الصفحات & المحتوي \\
\hline$\% r r$ & $\%$ ro, r & 1. & $\% r \cdot r$ & rr & حل المشكلات \\
\hline$\%$.rq & $\%$ \% , & 7 & $\%$ \% & r. & مقدمة فيجوال بيزك \\
\hline$\% r \cdot, 0$ & $\%$ \% , & 7 & $\% 19, v$ & 10 & ضبط خصائص أدوات التحكم \\
\hline$\% r r, 0$ & $\%$ \% , & 7 & $\% r r, \Lambda$ & 11 & نافذة الكود \\
\hline$\%$ & $\%$ & ra & $\%$ & vi & 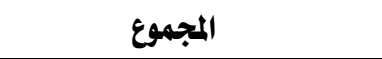 \\
\hline
\end{tabular}

الأوزان النسبية لجوانب التعله

\begin{tabular}{|c|c|c|c|c|c|c|}
\hline \multicolumn{2}{|c|}{ الأوزان النسبية } & \multicolumn{4}{|c|}{ مستوى الأهداف } & \multirow{2}{*}{ الموضوعات } \\
\hline النسبة & علد الأسئلة & حل المشكلات & مهارات & الفهم & التذكر & \\
\hline$\% r \cdot, 0$ & or & r. & 11 & 1. & ir & حل المكلات \\
\hline$\%$ & $M$ & $r$ & $\bar{v}$ & 0 & $\bar{v}$ & مقدمة لفة فيجوال بيزك دوت نت \\
\hline$\%, 0,0$ & $\wedge \wedge$ & $\wedge$ & ro & ro & r. & ضبط خصائص أدوات التحكه \\
\hline$\%$ & ir & $r$ & $\xi$ & $r$ & $r$ & 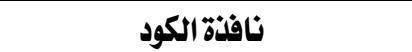 \\
\hline$\%$ & (1) & $r r$ & or & $\xi r$ & $\xi r$ & المجموع المجوع \\
\hline & & & & & & \\
\hline
\end{tabular}

تم حساب عدد المفردات لكل موضوع من الموضوعات كالتالي:

عدد المفردات لكل موضوع= (متوسط الأهمية النسبية × الوزن النسبي في كل خلية

$$
\text { فى جدول الأوزان النسبية لجوانب التعلم) ؛ . . }
$$

جدول المواصفات النهائي للاختبار التحصيلي

\begin{tabular}{|c|c|c|c|c|c|}
\hline الأوزان النسبية & \multicolumn{4}{|c|}{ مستوى الأهداف } & \\
\hline \multirow{2}{*}{ ع الأسئلة } & حل الشكلات & مهارات & الفهر & التذكر & \\
\hline & \multicolumn{4}{|c|}{ عدد الأسئلة } & \\
\hline 17 & 7 & $r$ & $r$ & $\xi$ & حل الشكلات \\
\hline$\xi$ & 1 & 1 & 1 & 1 & مقدمة لفة فيجوال بيزك دوت نت \\
\hline iv & 1 & $r$ & 0 & $\xi$ & ضبط خصائص أدوات التحكم \\
\hline$r$ & 1 & 1 & . & 1 & نافذة الكود \\
\hline$\xi$ & 9 & ir & 9 & 1. & المجموع \\
\hline
\end{tabular}




\section{Abstract}

The study aimed to investigate the effect of the use of software based on some cloud applications on the development of programming skills in the language of the Visual Basic for the prep school students. The study was conducted on a sample of (60) students divided into two groups, one experimental and one control. The researcher used (SPSS) program -to analyze the results; the Independent Samples Test to compare the average scores and the performance rate between the posttest and the pre-test in the achievement (Paired Samples Test) to compare the scores and the performance rate between the students of two groups in the achievement test and the performance rate on the pre and post tests. The research found that the students who used the software based on the cloud applications are better than students who studied in the traditional way at achieving the side Knowledge and performance of the performance side of the programming skills in Visual Basic 